\title{
Measurements and Analysis of Primary Ship Waves in the Stockholm Archipelago, Sweden
}

\author{
Björn Almström(1) and Magnus Larson * \\ Division of Water Resources Engineering, Lund University, P.O. Box 118, SE-22100 Lund, Sweden; \\ bjorn.almstrom@tvrl.lth.se \\ * Correspondence: magnus.larson@tvrl.lth.se
}

Received: 14 September 2020; Accepted: 21 September 2020; Published: 25 September 2020

\begin{abstract}
Primary ship waves generated by conventional marine vessels were investigated in the Furusund fairway located in the Stockholm archipelago, Sweden. Continuous water level measurements at two locations in the fairway were analyzed. In total, 466 such events were extracted during two months of measurements. The collected data were used to evaluate 13 existing predictive equations for drawdown height or squat. However, none of the equations were able to satisfactorily predict the drawdown height. Instead, a new equation for drawdown height and period was derived based on simplified descriptions of the main physical processes together with field measurements, employing multiple regression analysis to derive coefficients in the equation. The proposed equation for drawdown height performed better than the existing equations with an $R^{2}$ value of 0.65 , whereas the equation for the drawdown period was $\mathrm{R}^{2}=0.64$. The main conclusion from this study is that an empirical equation can satisfactorily predict primary ship waves for a large data set.
\end{abstract}

Keywords: ship waves; drawdown; ship wave measurement; predictive equations; restricted waterways

\section{Introduction}

Shorelines are important natural infrastructures along our coasts since they provide ecosystem services in the form of erosion mitigation, biological diversity, and recreational and aesthetic values [1]. However, these ecosystem services from shorelines in sheltered navigational fairways can be diminished by marine vessels, which introduce additional hydrodynamic forces in addition to wind-generated waves through the generation of ship waves. The ship waves can cause erosion [2], loss of biological habitats, reduce biodiversity [3], and decrease the perceived aesthetic values of the shore. Thus, to protect shorelines in navigational fairways, it is necessary to consider the hydrodynamic forces induced by ships [4].

Estimating ship waves can be done through measurements; however, the collected data will only include information from the period of the measurements and can therefore not be used for predicting ship waves outside the range covered by the data. Numerical modelling has successfully been used for quantifying ship waves during recent years [5-8]. However, models require input data not always available, skill in the specific numerical modelling software, and typically, substantial computational resources, thereby limiting the applicability for practitioners. Empirical models for predicting ship waves can, therefore, be useful for assessment of whether such waves may cause problems, especially in pilot studies, in the design phase of a shoreline protection project or for long-term assessment of ship wave impact on shorelines. The latter type of assessment is not feasible to perform through numerical modelling studies since it is computationally expensive and requires detailed hull geometries for many different ships. However, empirical equations have mainly been derived for navigational channels with uniform bathymetry and have often only been validated through laboratory or prototype 
experiments [2,9-11]. Hence, there is a knowledge gap regarding how well existing empirical equations perform in navigational channels with varying geometry.

The water level variation generated by a passing ship is in general separated into two systems consisting of primary waves and secondary waves $[12,13]$. The primary waves, due to their long period, are often more problematic in terms of shore and bank erosion [14-16]. The main aim of the present study is to predict the properties of primary ship waves in a navigational fairway through an archipelago with varying geometry using empirical equations. This was accomplished by evaluating the most commonly used empirical equations to predict drawdown height or squat using measurements from a navigational fairway in the archipelago of Stockholm, Sweden. However, in order to find an empirical equation for drawdown height that yielded better agreement with the measured data, a new equation was developed by considering the main governing parameters using regression analysis. In addition, an equation for the drawdown period was developed using a similar approach.

This paper starts with a general review of ship waves and the existing empirical equations for quantifying primary ship waves, focusing on the drawdown height. Thereafter follows a description of the field site together with the methods used for measuring and analyzing the primary waves. The results from the analysis and the evaluation of the existing empirical equations towards the data are presented. Then, the development and comparisons of the new empirical equations for drawdown height and period with the data are discussed. The paper ends with a discussion of the results and the conclusions.

\section{Ship Waves}

When a ship moves through water, the resistance of the hull creates a disturbance (Figure 1) consisting of primary and secondary wave systems $[12,13]$. The primary wave system includes the bow wave in the front and the stern wave at the end of the ship, with the drawdown wave generated along the ship in between those two waves [13]. Generation of the primary wave system, as explained by Bhowmik et al. [17], is a result of the ship pushing water in front of itself while moving forward. This water must return along the sides and under the keel in order to fill the void behind the ship as it moves forward, inducing higher velocities in the vicinity of the hull. This increase in velocity is enhanced in navigational fairways with a limited cross section relative to the cross section of the ship. The higher velocity near the ship creates a hydrodynamic pressure field that results in a sinkage and a trim of the ship, referred to as squat, as well as a depression of the water surface along and away from the hull, referred to as drawdown, depending on the local balance between kinetic and potential energy. The squat of a ship should correspond to the drawdown immediately at the ship, which tends to be the maximum drawdown observed; thus, some distance away from the ship the drawdown is smaller than the squat. For relatively wider fairways, the drawdown generated by the ship is limited to an area around it, and the generated drawdown will propagate as a depression wave, being transformed depending on the bathymetric conditions [18]. In the derivation of equations for drawdown, especially for narrow channels or fairways, a uniform drawdown height is typically assumed for simplification, implying that the drawdown and the squat are equal [19].

In Figure 1, the definition used in this paper for drawdown height and period is shown. The drawdown height is defined as the distance from the still water level to the lowest level in the primary wave. The period of the drawdown is defined as the period between two consecutive zero crossings; thus, it is different from the typical definition of the wave period, which would include the period between two zero down- or up-crossings.

The drawdown height and squat can be predicted using empirical equations, which usually include parameters related to ship characteristics (e.g., block coefficient, draft, length, speed, submerged cross section, volume, beam, and distance to shore) and fairway geometry (e.g., cross section, water depth, hydraulic depth, and top width) $[10,20]$. These parameters, except for the block coefficient, can be obtained from the automatic identification system (AIS) and sea charts. The block coefficient is challenging to retrieve information about since it depends on the hull shape that is unique for each ship 
and typically only known by the ship builders. Thus, empirical equations not including this parameter are easier to apply, since all required input is readily available. Nevertheless, empirical equations incorporating the block coefficient are included in this paper, employing a constant value for all ships observed at the field site, to assess their usefulness for engineering applications.

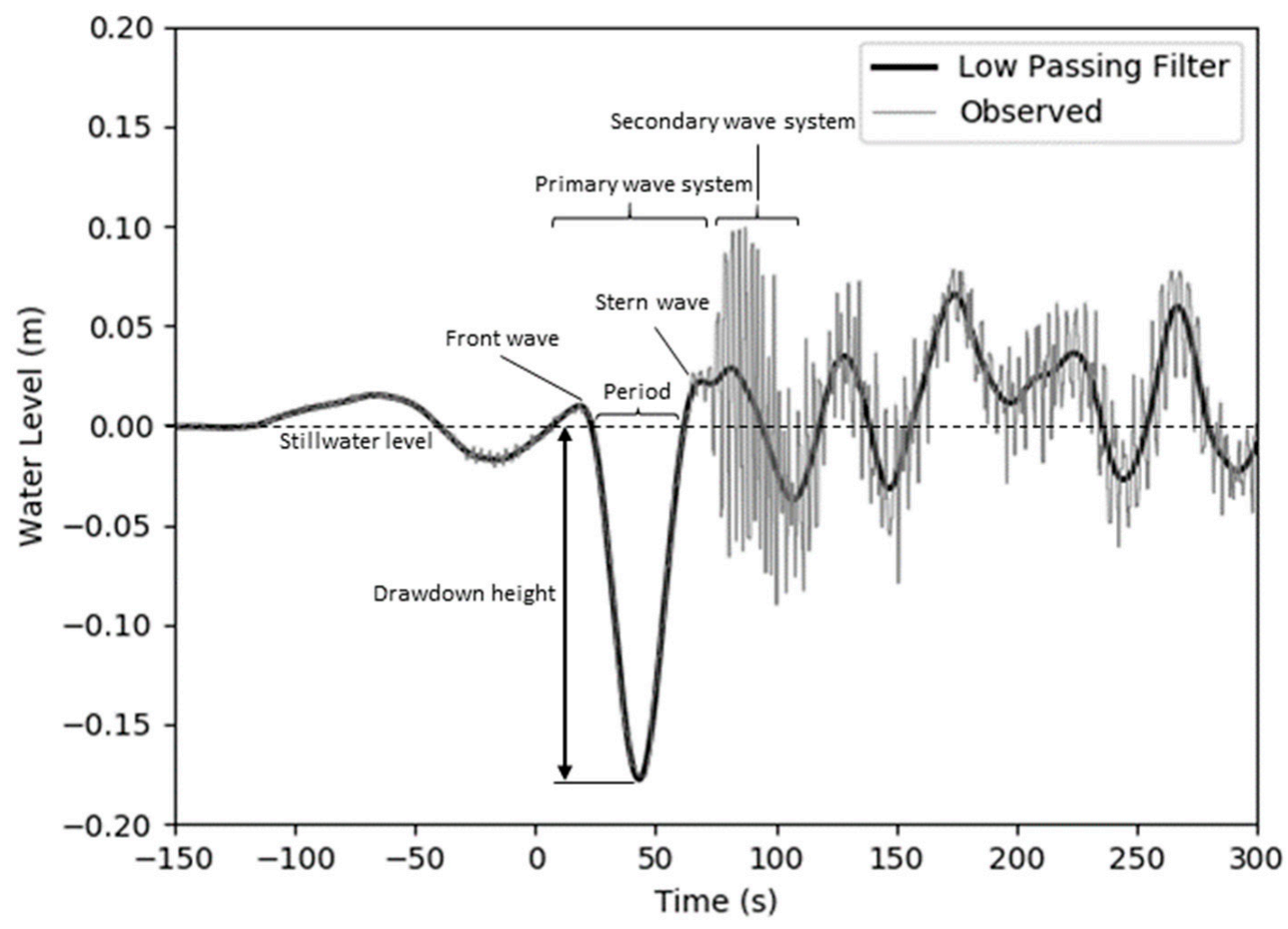

Figure 1. A typically recorded wave system during a ship passage illustrating the terminology used in this paper. Time equal zero indicates when the ship passes in front of the measuring station. The grey line displays the actual water level measurements, whereas the thick black line shows the water level after a low-pass filter has been applied.

Eight empirical equations for predicting drawdown height were identified from the literature. In addition, five equations for squat studied by Briggs [20] were also included, since the squat closely relates to the drawdown, as previously discussed. The empirical equations evaluated here are described below by grouping them based on if they originally were developed to predict drawdown or squat. No empirical equations to predict the period for primary waves were found in the literature.

\subsection{Empirical Equations for Drawdown Height}

An early study to develop an equation for the drawdown was conducted by Schijfs [11], who employed the same approach as Thiele [21] (the equation is presented in Appendix B, see Equation (A1)). This approach was also used by Schiereck [13] and Gates and Herbich [22] to estimate the drawdown and the squat, respectively. The theoretical expression for the drawdown was based on the Bernoulli equation and the continuity equation, assuming a constant, uniform drawdown (or squat) and return current over the channel width. Energy losses around the bow of the ship were neglected. Since the equation assumes uniform drawdown and return velocity over the channel cross-section, there is no parameter considering the transformation (i.e., typically an attenuation) of the primary wave as it propagates to the shore.

Hochstein [23], as described by Hochstein and Adams [24], describes the drawdown as a function of the velocity head in the Bernoulli equation and two correction factors (Equation (A2)). The first correction factor considers the blockage ratio $\left(\mathrm{A}_{\mathrm{s}} / \mathrm{A}_{\mathrm{c}}\right)$. The second correction factor is a function of 
the ratio between the vessel speed and the critical velocity of the ship. The critical velocity is defined by the celerity of a shallow water wave and a constrainment factor that is a function of the blockage ratio and the ratio between the vessel length and beam. Unfortunately, Hochstein and Adams [24] gave no further information on how the equation for drawdown was derived. As is the case of Schijfs, the equation does not include attenuation of the primary wave as it propagates towards the shore.

Contrary to the previous two equations, Gelencser [14] included the attenuation of the primary wave by adding a parameter involving the distance between the ship and the shore (Equation (A3)). Gelencser's equation was derived through dimensional analysis using Buckingham's theorem and applying regression towards observed drawdown height from model and prototype experiments of the St. Lawrence Seaway to extract coefficient values. However, the equation proposed by Gelencser [14] is not dimensionally consistent and the derivation of the equation is not transparent. Since this equation is not dimensionally consistent, it was not considered meaningful to include it in the comparison, but it is given mainly for sake of completeness.

Dand and White [25] performed scale model experiments for ships in the Suez Canal. These experiments yielded an empirical equation based solely on the blockage ratio for which coefficients were derived through regression from the scale model experimental results. The drawdown was normalized with the velocity head in the Bernoulli equation (Equation (A4)). Bhowmik et al. [17] measured drawdown on the Illinois and Mississippi Rivers and tested empirical equations from Schijf [11], Dand and White [25], Gelencser [14], and Gates and Herbich [22]. However, Bhowmik found a better equation for the drawdown height by employing multivariate regression analysis on the measured data (Equation (A5)), by elaborating on Dand and White's [25] equation with a non-dimensional group of the ratio between the ship length and the distance from ship to shore.

Maynord [10] developed an analytical method (Equations (A6) and (A7)) for predicting drawdown from commercial ships in navigable fairways based on data from prototype and physical models of the Ohio, Illinois, and Upper Mississippi Rivers. The equation incorporates the ship limiting speed developed by Schijfs [11] and involves two different equations for the drawdown depending on which side of the fairway centerline the ship sails. The difference is in the expression for the attenuation of the wave, which is a function of the ratio between distance from the shoreline and top width of the fairway.

Kriebel et al. [9] presented an equation (Equation (A8)) for the drawdown height based on physical model experiments, using two types of ships with block coefficients of 0.6 and 0.8. Kriebel et al. [9] used a modified Froude number based on ship length and also included the ship block coefficient.

The Rock Manual [26] recommends an empirical equation for drawdown height (Equation (A9)) but does not mention how it was derived or its origin. The validity range of the equation is $A_{c} / A_{\mathrm{S}}<5$ and $T / B<10$, based on the assumption of a one-dimensional flow field. For larger ratios, the flow field should be considered two-dimensional according to CIRIA (Construction Industry Research and Information Association) [26].

\subsection{Empirical Equations for Squat}

Briggs et al. [20] summarized the most commonly used squat equations presented in the PIANC (The Permanent International Association of Navigation Congresses) report WG30 as well as from later research. These equations are included in the present study.

Originally Tuck [27] derived an equation for squat based on slender body theory, subsequently improved by Hooft [28] and later extended by Huuska [29], through adding a correction factor, $\mathrm{K}_{1}$, for different types of channels developed by Guliev [30]. Huuska's equation (Equation (A10)) is recommended by ICORELS (the International Commission for the Reception of Large Ships in unrestricted or open channels) [31]. The equation is based on the depth Froude number, dimensions of the submerged ship hull, and two correction factors. One correction factor is the squat constant of which $C_{s}=2.40$ is typically used, and the other correction factor $K_{1}$ is given as a function of the blockage ratio $(\mathrm{As} / \mathrm{Ac})$ and the trench height ratio $\left(\mathrm{h}_{\mathrm{T}} / \mathrm{Y}\right)$ in Huuska [29]. 
Barrass [32,33] made a regression analysis involving measured squat, using over 600 laboratory and prototype experimental cases for all types of channels. The equation (Equation (A11)) consists of the parameters ship block coefficient, blocking ratio, and the ship speed in knots.

Yoshimura [34], described by Briggs et al. [20], developed a squat equation for open or unrestricted channels based on parameters such as ship hull geometrics, vessel speed, and channel depth (Equation (A12)). According to Briggs et al. [20] it estimates conservative values on the squat.

Römisch [35], described by Briggs et al. [20], made physical experiments on ship squat and derived an equation based on their experimental data. Römisch equation for the squat is calculated from the ship draught, which is corrected with factors for ship speed, ship shape, and squat at critical speed. The formula can be used for calculating both the bow (Equation (A13)) and the stern squat (Equation (A14)).

Eryuzlu et al. [36], described by Briggs et al. [20], conducted a series of model experiments and field measurements of cargo ships and bulk carriers in restricted and unrestricted channels, from which an empirical equation for the squat was developed. The equation (Equation (A15)) uses a ship draught Froude number, ratio between channel depth and ship draught, and a correction factor for the channel width relative to ship beam.

\section{Field Measurements}

\subsection{Study Site: Furusund Navigational Fairway}

Ship data for the present study were collected in the Furusund fairway, located in the inner part of the Stockholm archipelago in the Baltic Sea (Figure 2). Due to its location, the fairway has a non-uniform geometry with irregular bathymetry, many islands, and an irregular coastline. There is negligible astronomical tide in the Baltic Sea and the meteorological forcing is mainly driving the sea level changes in this area. According to a nearby located water level station (Stockholm - 2069) with a time series from 1889 until present, the maximum observed level is $+1.16 \mathrm{~m}$ and the minimum observed level is $-0.69 \mathrm{~m}$ relative to the mean sea level.

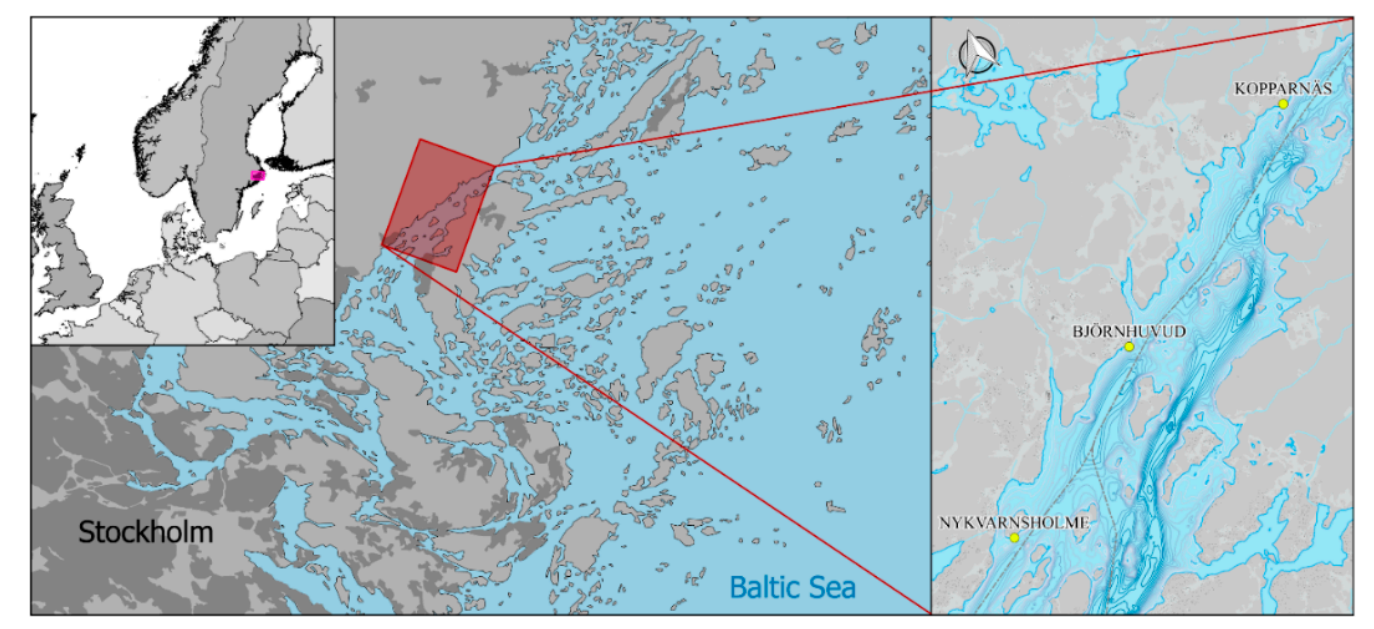

Figure 2. An overview of the Furusund fairway with the locations of ship wave measurements shown as yellow markers.

The wind-generated waves are small, due to short fetches and lack of swell. Ship waves are therefore a significant contributor to the wave forces acting on the shores. Ship traffic in the Furusund fairway is intense, with approximately 6500 ships passing through in 2014 [37]. The intensity of traffic, as well as ship size, have increased notably since the 1980s [38]. The increase in ship traffic has generated higher wave energy impacting on the shores, resulting in retreating reed belts, fine-sediment beaches being replaced by more wave resistant cobble beaches, and the emergence of larger erosion bluffs [39-42]. The ships consist mainly of large passenger ferries, traveling the fairway twice a day, 
and even larger cruise ships during the summer months. The more frequent large passenger ferries are approximately 150-220 m long, $30 \mathrm{~m}$ wide, and have a draft of about $7 \mathrm{~m}$. The cruise ships are larger than the regular passenger ships and are up to $330 \mathrm{~m}$ long, $40 \mathrm{~m}$ wide, and draft up to $9 \mathrm{~m}$. For example, Figure 3 shows one of the larger passenger ships (Baltic Princess), as well as one of the cruise ships (MSC Prezoria), sailing in the Furusund fairway.

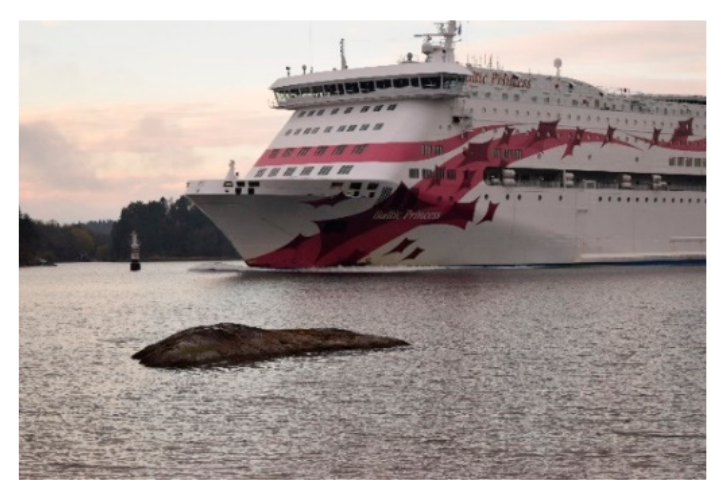

(a)

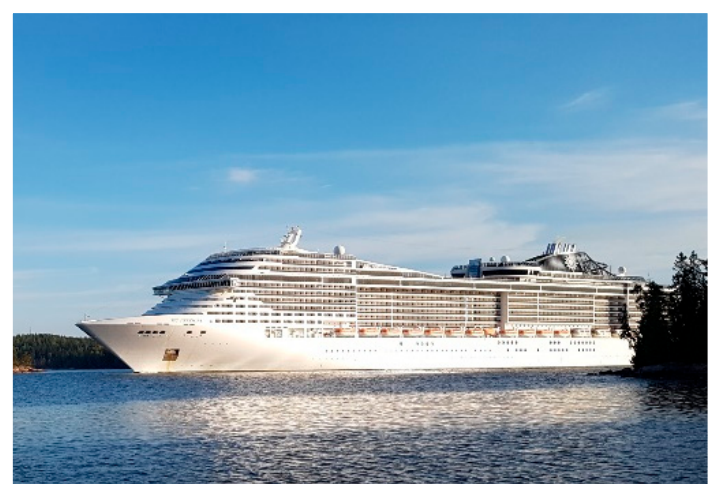

(b)

Figure 3. (a) Example of one of the larger passenger ferries, Baltic Princess, and (b) a large cruise ship, MSC Prezoria, sailing through the Furusund fairway.

\subsection{Experimental Setup and Procedure}

The field measurements were carried out in 2014 as a part of a study on ship waves in the Furusund fairway [43]. The methodology employed to measure and derive data on ship waves involved the following steps: (1) measure the water level continuously at two locations known to experience ship waves, (2) collect AIS (automatic identification system) (AIS)data for the period of the measurement campaign, (3) combine the water level measurements with the AIS data to obtain water level time series for each recorded ship passage, (4) apply a low-pass filter on the water level time series from each individual ship passage to separate the primary ship wave from the secondary waves and the wind-generated waves, and (5) manually select water level time series of high quality showing a clear primary wave signal for further analysis.

The continuous water level measurements were made with a sampling frequency of $4 \mathrm{~Hz}$ using a capacitance level probe, with sensor accuracy in the range of millimeters and a measurement error less than $2 \%$. The probe was mounted on already existing piers at two locations in the fairway, Björnhuvud and Nykvarnsholme [43] (Figure 4).

At Björnhuvud, measurements were made about $7 \mathrm{~m}$ from the shore where the depth was $3.5 \mathrm{~m}$ (Figure 4a), during the period 13 June to 3 July in 2014 [43]. Distance to the sailing line from the measuring location is approximately $200 \mathrm{~m}$, and the smallest fairway cross section (Figure 4a) has an area of $4800 \mathrm{~m}^{2}$ and a width of approximately $300 \mathrm{~m}$. The hydraulic depth of this cross section is $16 \mathrm{~m}$.

At Nykvarnsholme, the measurement device was installed about $8 \mathrm{~m}$ from the shore where the depth was about $3 \mathrm{~m}$ (Figure 4b) [43]. Measurements were made during the period 2 to 28 August 2014. Distance to the sailing line was $120 \mathrm{~m}$, and the smallest cross section has an area of $4400 \mathrm{~m}^{2}$ and a width of approximately $370 \mathrm{~m}$. The hydraulic depth of this cross section is $12 \mathrm{~m}$.

The bathymetry in the Furusund fairway, which was made available by the Swedish Maritime Administration as a $10 \times 10 \mathrm{~m}$ grid, has a irregular geometry and includes islands as well as submerged islets (see Figure 4).

The AIS data were used to identify ships causing primary wave events and to collect parameter values characterizing these ships, such as draft, speed, heading, course, type of ship, and position. AIS data were retrieved from the Swedish Maritime Administration with a resolution of $10 \mathrm{~s}$ between 
each ship position registration. Information about individual ship lengths and widths, parameters not included in AIS data, were retrieved from the website www.marinetraffic.com.

For each ship passage, water level measurements were extracted five minutes prior to and ten minutes after the passage. A manual selection of suitable ship wave signals was made to exclude erroneous measurements from the analysis and only use reliable observations. Errors were commonly associated with seaweed interfering with the capacitance probe [43]. In order to eliminate secondary waves and wind-generated waves, a fourth-order Butterworth low-pass filter with a cut off frequency of $0.067 \mathrm{~Hz}$, which was found to best reproduce the primary waves, was applied to the recorded water level time series from each ship passage. The drawdown height was determined by the minimum water level of the low pass filter signal for each ship passage relative to the still water level, which was defined as the mean water level $30 \mathrm{~min}$ before and after each primary wave event. The period of the primary wave was defined as the time between the front wave and the stern wave, as shown in Figure 1. Thus, a database was compiled by taking all the primary waves larger than $5 \mathrm{~cm}$ and coupling them with the information from the AIS about the specific ship generating each wave event.

(a)
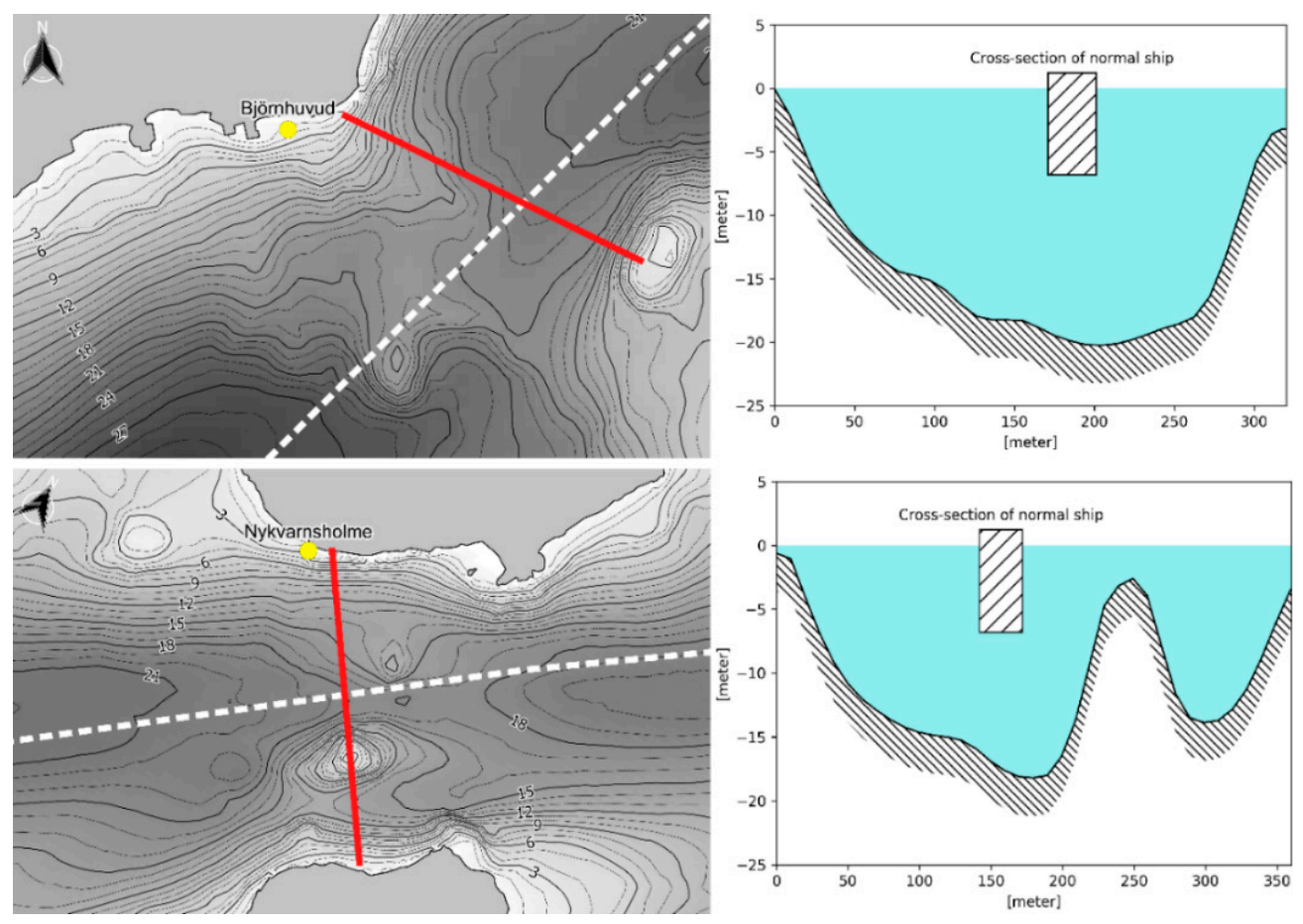

Figure 4. Bathymetry at Björnhuvud (a) and Nykvarnsholme (b) together with the smallest cross section in the fairway shown with a red line. The center line of the fairway is marked with a dashed white line. The profile of the smallest cross section for each location is shown to the right (note that a distorted scale is used). The yellow marks indicate the location of the measuring station.

\section{Results}

\subsection{Overview of Collected Data}

Analysis of the measurements from the two-month long field campaign resulted in a database containing 466 identified primary waves with the associated properties for each ship passage. Summary information from this data base is given in Table 1. In the table, the ships have been categorized according to their type in agreement with AIS (A-C) and the passenger ships were further divided into three subcategories (A1-A3) based on their length. Most ships sailed with similar speeds, varying from 8.6 to 12.3 knots, due to the speed restriction in the fairway. Moreover, the maximum draft allowed is limited in the fairway to $9 \mathrm{~m}$, explaining the lack of ships with deeper draft. The sailing distance from the shore is also similar for most ships because of the bathymetry requiring the same 
sailing course for the ships. During the measurement period, 22 individual ships generated the 466 primary wave events. The relatively low number of individual ships relative to the high number of primary waves is explained by the many passenger ships being in regular traffic. Even though the primary waves are generated by relatively few ships which are sailing at comparable speeds during each passage, there is a significant variation in the drawdown height and wave period within each category.

Histograms for all drawdown wave heights and periods can be seen in Figure 5a,b. The wave height seems to have a right-skewed distribution, whereas the wave periods are more evenly distributed. The same types of distributions emerge when data are sorted based on ships being inbound (heading south) or outbound (heading north), as shown in Figure $5 c-f$. However, inbound ships typically generate larger drawdown and longer wave periods than outbound ships; thus, a detailed analysis was performed to explain this behavior. The analysis showed that this difference between inbound and outbound ships only occurred at Nykvarnsholme, whereas at Björnhuvud the drawdown did not vary depending on the direction of the ships. It was concluded that the cause of the drawdown being larger for incoming ships at Nykvarnsholme was due to the varying bathymetry at the location and its influence on the drawdown being generated. Because of the distance that the drawdown wave has to travel from the ship to the shoreline, the recorded wave is not generated at the same location for in- and outbound ships. Drawdown waves can be considered as a shallow water wave travelling with a speed of $c=\sqrt{g Y}$, where $c$ is the wave celerity and $Y$ is the water depth. If the depth varies linearly between $Y_{1}$ and $Y_{2}$, the representative wave celerity for the travel time to shore is given by $c=\frac{1}{2}\left(\sqrt{g Y_{1}}+\sqrt{g Y_{2}}\right)$, for a small slope. With the prevailing water depths, it will therefore take a wave about $20 \mathrm{~s}$ to propagate from the ship to the shoreline, since the distance between the ship and the shoreline at Nykvarnsholme is approximately $160 \mathrm{~m}$. In addition, the drawdown wave is also expected to propagate in the direction of the ship with its speed. Average speed of the ships passing Nykvarnsholme is 10.5 knots, so the drawdown wave travels approximately $100 \mathrm{~m}$ in the sailing direction before it reaches the shore. Hence, the observed drawdown wave is not generated directly in front of the measuring location at Nykvarnsholme. Instead, it originates about $100 \mathrm{~m}$ north or south of the location depending on whether the ship is in- or outbound, respectively. Since bathymetry at Nykvarnsholme is highly irregular (Figure 4) drawdown waves are generated at different depths and cross sections, resulting in larger drawdown waves for incoming traffic.

Table 1. Summary of field measurements of primary waves for different ships generating such waves. Given values, except the number of ship passages and recorded primary waves, are average values and within brackets are the minimum and maximum values given. Statistics of ship parameters only include those ship passages resulting in the registration of a primary wave event.

\begin{tabular}{|c|c|c|c|c|c|c|c|c|}
\hline Category of Ship & $\begin{array}{l}\text { No. of Primary } \\
\text { Waves }>5 \mathrm{~cm}\end{array}$ & $\begin{array}{c}\text { Ship Draft } \\
\text { (m) }\end{array}$ & $\begin{array}{l}\text { Ship } \\
\text { Beam } \\
(\mathrm{m})\end{array}$ & $\begin{array}{l}\text { Ship } \\
\text { Length } \\
\text { (m) }\end{array}$ & $\begin{array}{l}\text { Ship } \\
\text { Speed } \\
\text { (knt) }\end{array}$ & $\begin{array}{c}\text { Distance } \\
\text { from Shore } \\
\text { (m) }\end{array}$ & $\begin{array}{l}\text { Drawdown } \\
\text { Height } \\
\text { (m) }\end{array}$ & $\begin{array}{l}\text { Wave } \\
\text { Period } \\
\text { (s) }\end{array}$ \\
\hline $\begin{array}{l}\text { A2: Passenger ship; } \\
\text { length } 200-250 \mathrm{~m}\end{array}$ & 191 & $6.8(6.3-7.1)$ & $\begin{array}{c}31 \\
(29-32)\end{array}$ & $\begin{array}{c}211 \\
(203-218)\end{array}$ & $\begin{array}{c}10.9 \\
(8.6-12.3)\end{array}$ & $\begin{array}{c}169 \\
(141-250)\end{array}$ & $\begin{array}{c}0.15 \\
(0.05-0.32)\end{array}$ & $\begin{array}{c}46 \\
(24-74)\end{array}$ \\
\hline $\begin{array}{l}\text { A3: Passenger ship; } \\
\text { length }>250 \mathrm{~m}\end{array}$ & 32 & $8.0(7.2-8.9)$ & $\begin{array}{c}36 \\
(32-38)\end{array}$ & $\begin{array}{c}281 \\
(252-317)\end{array}$ & $\begin{array}{c}9.9 \\
(8.8-10.7)\end{array}$ & $\begin{array}{c}164 \\
(145-200)\end{array}$ & $\begin{array}{c}0.17 \\
(0.05-0.29)\end{array}$ & $\begin{array}{c}57 \\
(34-81)\end{array}$ \\
\hline C: Tanker ship & 1 & 8.0 & 24 & 170 & 9.1 & 162 & 0.07 & 42 \\
\hline
\end{tabular}

In the ship wave data base, there are eight parameters coupled to each primary wave event: ship speed, draft, length, beam, cross section, modified cross section considering cases when ship heading differs from its course, volume, and distance from the sailing line to the shoreline. Correlation between these parameters and the wave height, as well as the wave period, were made using a Spearman rank correlation analysis (Table 2). The highest correlation was obtained for the parameters related to the ship dimensions, such as length, volume, and cross section. It is not surprising that parameters related to ship dimensions are correlating well with the drawdown since larger ship 
dimensions increase the ship blockage ratio. More surprising was that speed gave rather low correlation, even though it is often mentioned in the literature [20] as one of the more important parameters for drawdown height. The low correlation can most likely be explained by the speed regulation in the fairway reducing the range of observed speeds. Table 2 also shows that a marked negative correlation exists between the distance of the ship to the shoreline and the wave height, indicating attenuation of the waves when propagating towards the shore. Hence, empirical equations including the distance should predict wave heights better at the study sites than equations not including this parameter. Concerning the wave period, correlations with the studied parameters are lower than for the height. Only draft, ship cross-section and speed exhibit correlation coefficients of 0.39 or higher. For speed, the correlation is inverse, indicating that the wave period is becoming shorter with increased vessel speed for the range of values obtained.

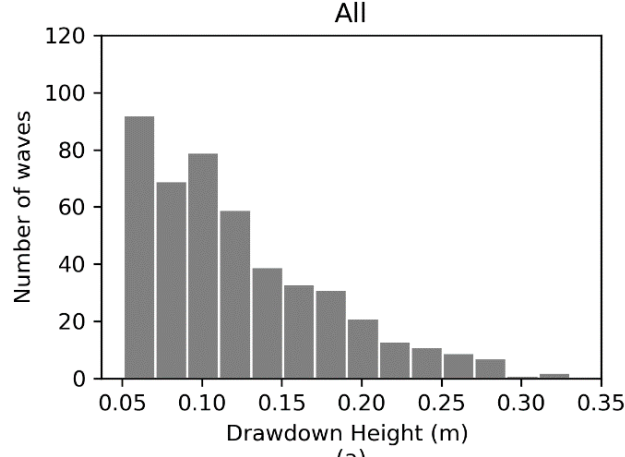

(a)

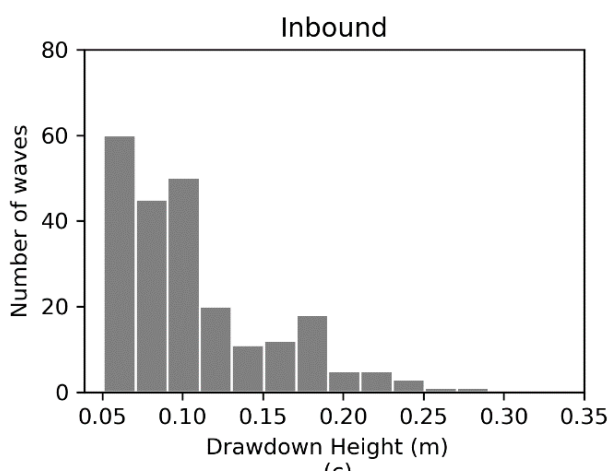

(c)

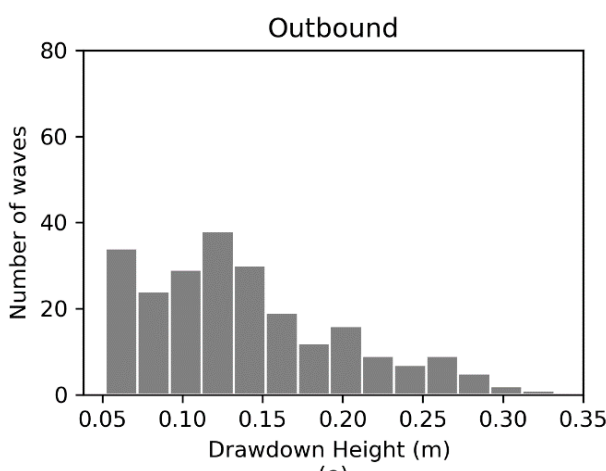

(e)

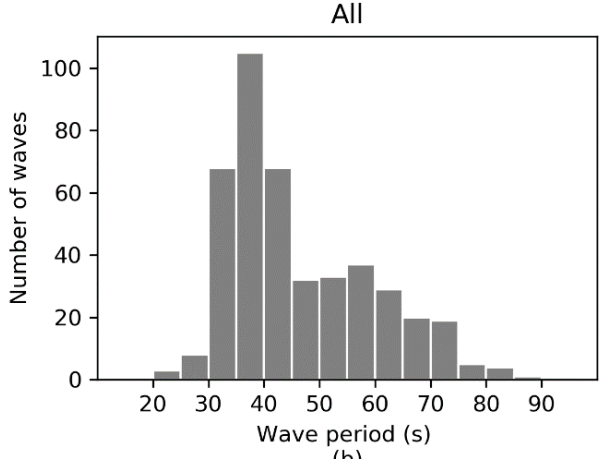

(b)

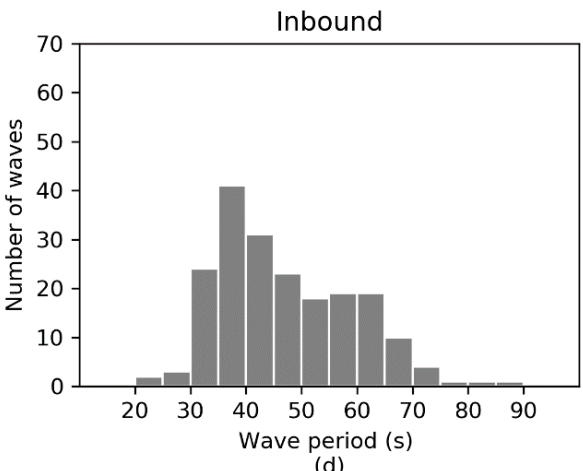

(d)

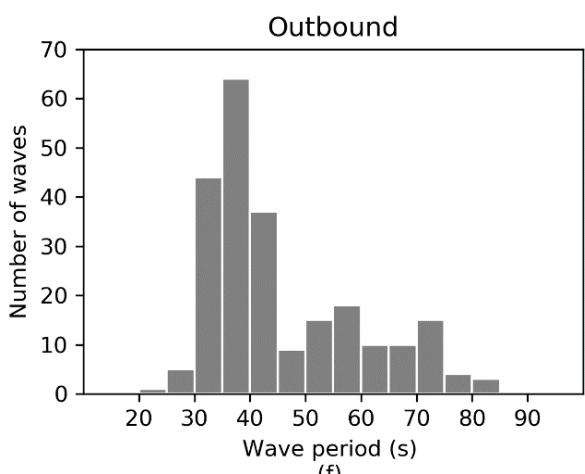

(f)

Figure 5. (a) Histogram of drawdown height at Nykvarnsholme and Björnhuvud for all inbound and outbound ship passages. (b) Histogram of wave period for all ship passages. (c) Histograms of drawdown height for inbound traffic. (d) Histograms of wave period for inbound ships. (e) Histograms of drawdown height for outbound ship passages. (f) Histograms of wave period for outbound ships. 
Table 2. Spearman rank correlation coefficient for drawdown wave height and period versus different studied ship parameters.

\begin{tabular}{ccccccccc}
\hline & \multicolumn{7}{c}{ Spearman Rank Correlation Coefficient } \\
\cline { 2 - 9 } & Beam & Distance & Draft & Length & Speed & Cross-Section & Volume & Drawdown Height \\
\hline Drawdown height & 0.39 & -0.53 & 0.23 & 0.51 & 0.13 & 0.26 & 0.46 & - \\
Wave period & 0.32 & 0.32 & 0.43 & 0.18 & -0.40 & 0.42 & 0.27 & -0.34 \\
\hline
\end{tabular}

The ship block coefficient was not included in the correlation analysis due to lack of information on this parameter for the studied ships. To investigate the importance of the ship block coefficient, one of the more frequently passing ships (Baltic Princess) in the Furusund fairway with 59 passages during the measurement period, was selected for more detailed analysis. This represents a case where the block coefficient did not influence the result. Spearman rank correlation was calculated for the only two varying parameters in the case of passages by this ship, namely distance and speed. In Figure 6, drawdown height and period are displayed as functions of these two parameters. There seems to be a correlation between distance and drawdown, but there is no strong correlation between distance and wave period. Speed is shown to be a weak parameter for predicting drawdown height as well as wave period for this ship, most likely due to speed restrictions present in the fairway. This analysis demonstrates that the ship block coefficient cannot be a primary cause for the scatter in the data since analysis of a single ship exhibits scatter as well.

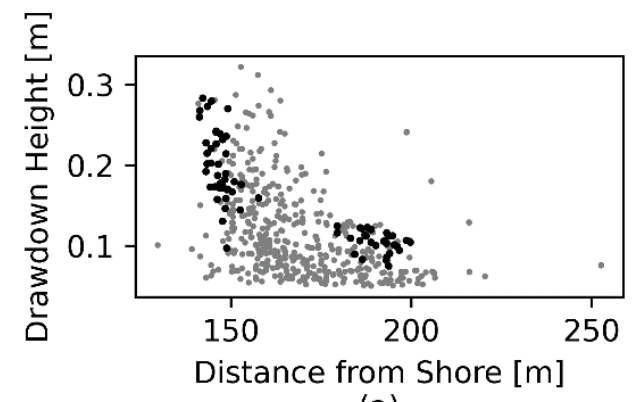

(a)

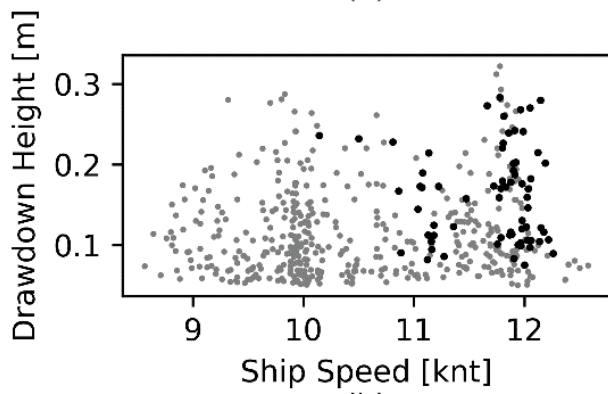

(b)

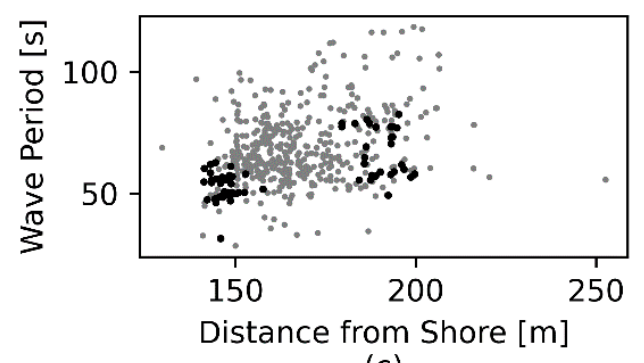

(c)

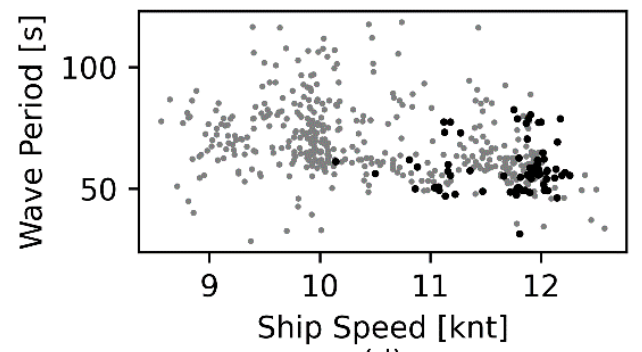

(d)

Figure 6. Drawdown height $(\mathbf{a}, \mathbf{b})$ and wave period $(\mathbf{c}, \mathbf{d})$ as functions of distance from the sailing line to shore and ship speed. Black dots mark a particular ship (Baltic Princess) and grey dots mark all the ships. As for the case of all ships, there seems to be a correlation between distance and drawdown when looking at a single ship. However, no strong correlation exists for ship speed.

Drawdown heights differ depending on the location, as shown in Figure 7. Drawdown with heights of up to $0.32 \mathrm{~m}$ is observed at Nykvarnsholme, whereas the drawdown never exceeds $0.14 \mathrm{~m}$ at Björnhuvud. The difference is probably related to the smaller cross-sectional area at Nykvarnsholme, the shallower depth at Nykvarnsholme, and the fact that ships sail closer to Nykvarnsholme (distance between 130-216 m) than to Björnhuvud (distance between 151-253 m). 

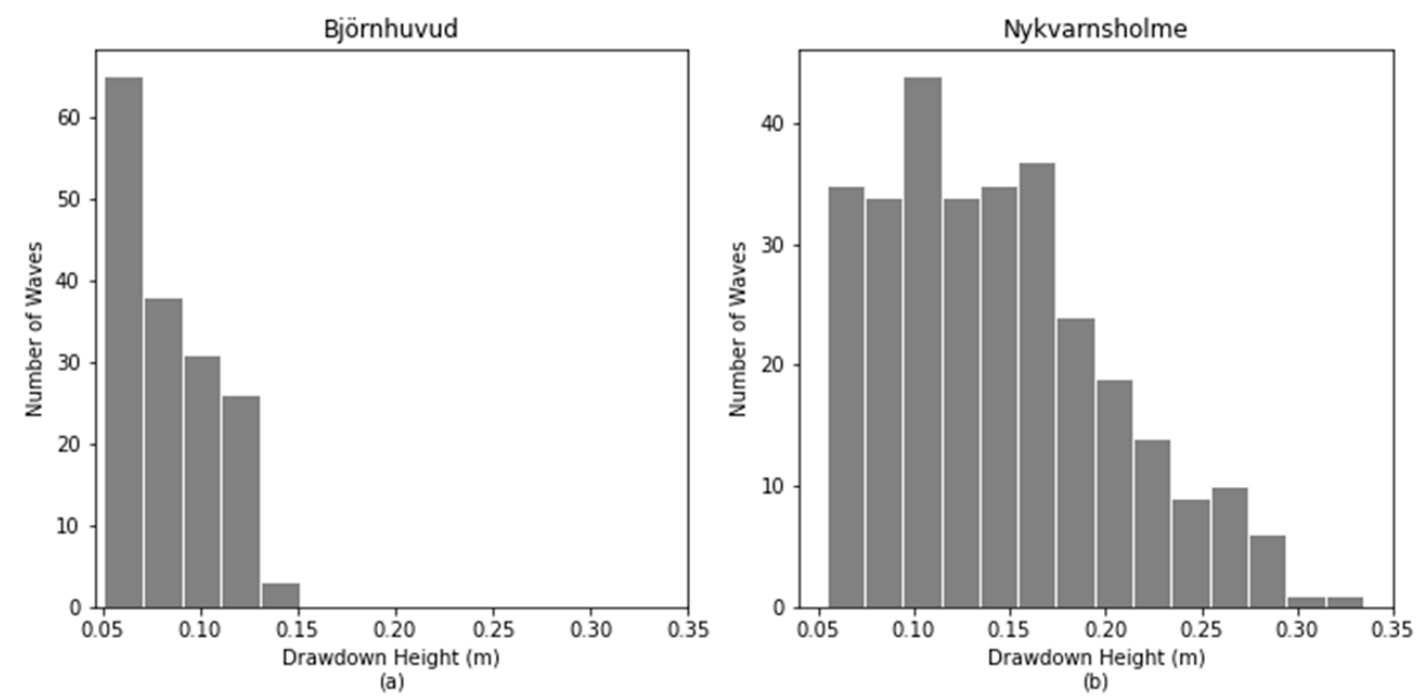

Figure 7. Histogram of measured drawdown for Björnhuvud (a) and Staboudde (b).

\subsection{Evaluation of Existing Empirical Equations}

Numerous empirical formulas have been derived for drawdown height or squat, and the most commonly used equations, presented previously, were employed to predict the measured drawdown heights in the current data set. Even though the selected equations were not explicitly developed for the rather complex conditions prevailing at Nykvarnsholme and Björnhuvud, it was still considered meaningful to evaluate their performance for such conditions, since these equations are the ones available to predict drawdown if numerical models are not employed.

The existing empirical equations were applied for the data set and the agreement was quantified using the coefficient of determination $\left(R^{2}\right)$, see Figures 8 and 9. If the ship block coefficient was included in an equation, it was given a value of 0.66 , assumed to be constant for all ships. This value corresponds to the ship block coefficient for the Baltic Princess, which is one of the passenger ferries frequently trafficking the fairway that is assumed to have a typical hull design for many of the ships in the fairway. In the comparison, four equations-namely Hochstein $\left(R^{2}=0.48\right)$, Dand and White $\left(R^{2}=0.43\right)$, Bhowmik $\left(R^{2}=0.40\right)$, and Schijfs $\left(R^{2}=0.31\right)$-yielded $R^{2}$ values higher than zero. Hochstein gave the highest $R^{2}$ value, but failed to reproduce the larger drawdown waves, whereas the Shijfs equation was better in describing larger waves. Two other equations gave a low mean absolute error $(5 \mathrm{~cm})$, that is, Kriebel and Maynord, but they had $\mathrm{R}^{2}$ values lower than zero due to a large scatter for Kriebel and a general underestimation for Maynord. The equations derived originally for drawdown had a lower mean absolute error compared to the squat equations. All squat equations overestimated the drawdown (Figure 9), which is expected since they yield the maximum possible drawdown height in the near field of the ship, not describing any decrease in height that often occurs as the wave propagates towards shore.

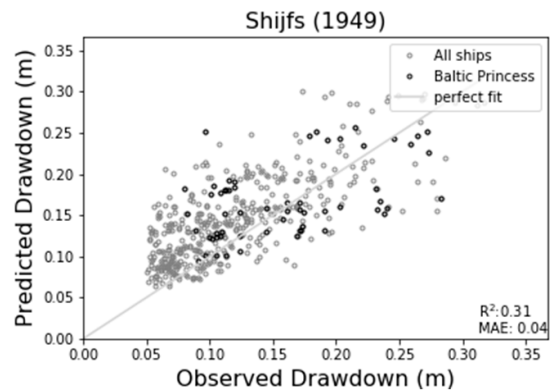

(a)

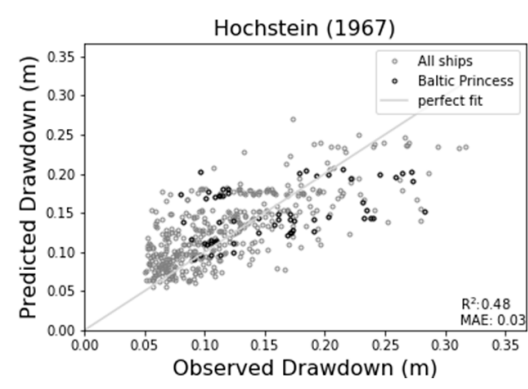

(b)

Figure 8. Cont. 


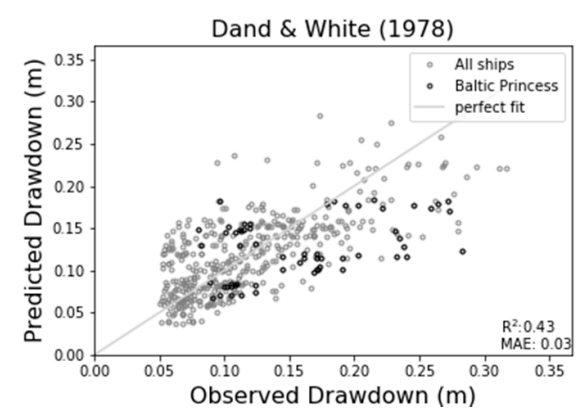

(c)

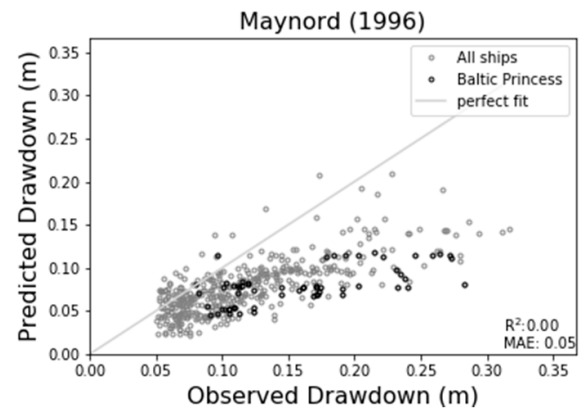

(e)

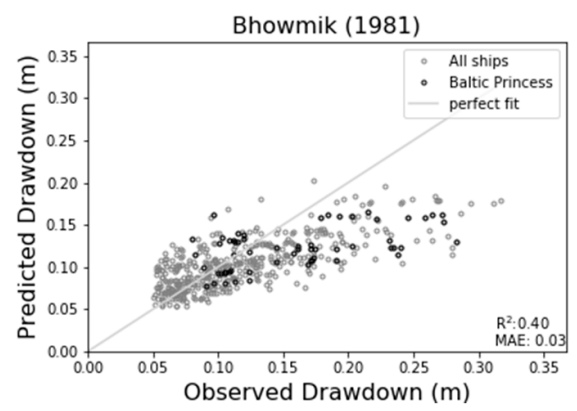

(d)

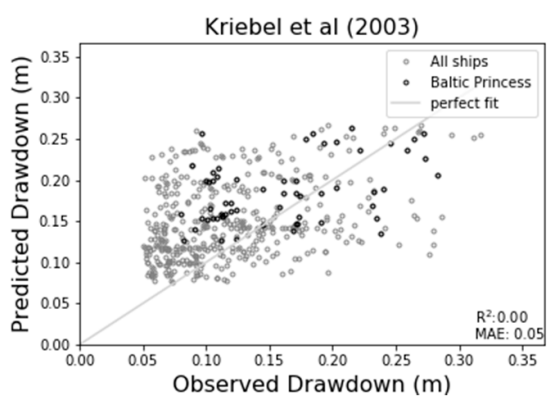

(f)

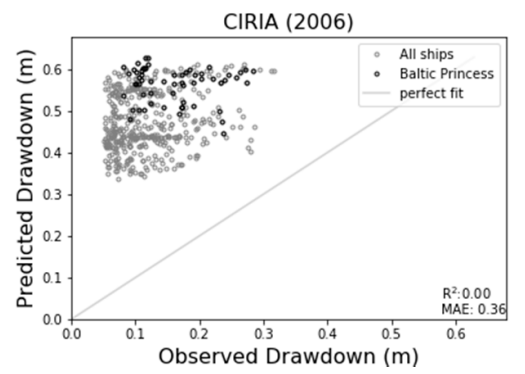

(g)

Figure 8. Calculated drawdown height with empirical equations versus measured drawdown height at Nykvarnsholme and Björnhuvud for the existing drawdown equations of Shijfs [11] (a); Hochstein [24] (b); Dand \& White [25] (c); Bhowmik [17] (d); Maynord [10] (e); Kriebel [9] (f); and CIRIA [26] (g) Grey markers represent all ships, whereas black markers only show data for the ship Baltic Princess. The drawdown from the single ship is included to show that the scatter is not related to the lack of information about the ship hull coefficient. The grey line displays the perfect fit between measured and predicted drawdown.

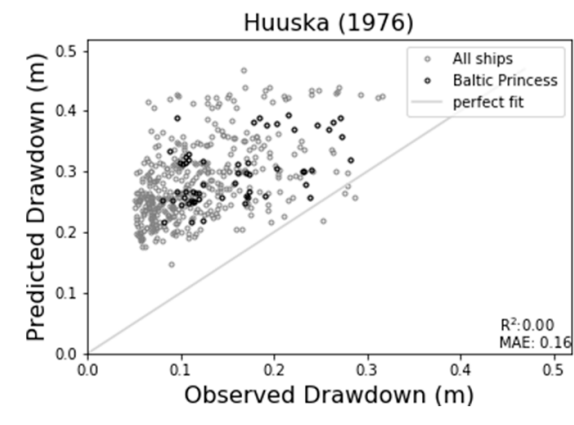

(a)

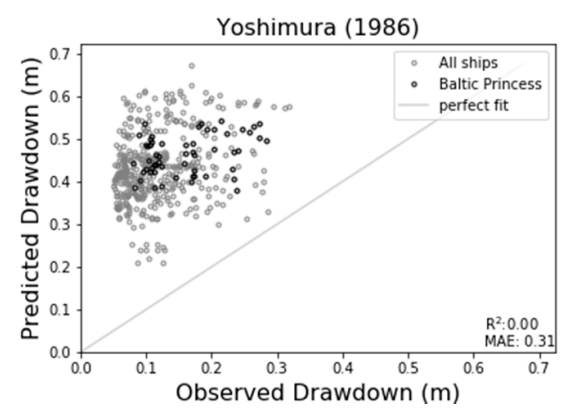

(b)

Figure 9. Cont. 


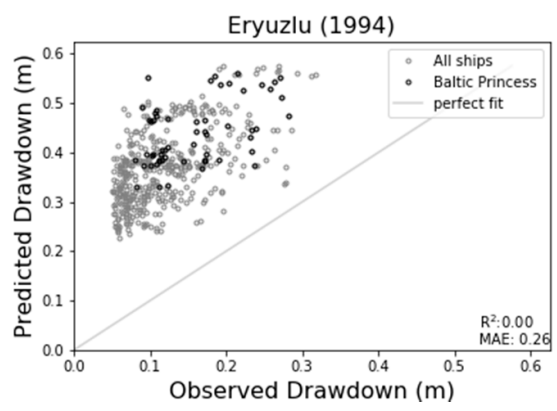

(c)

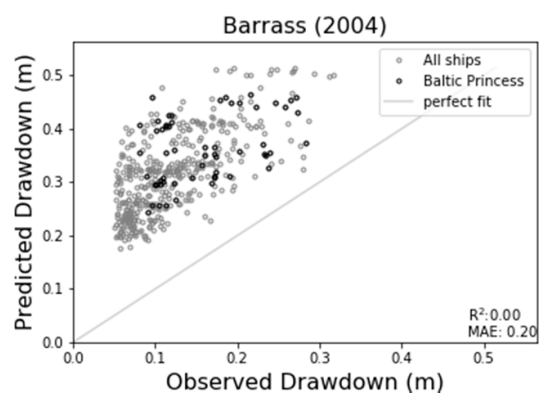

(d)

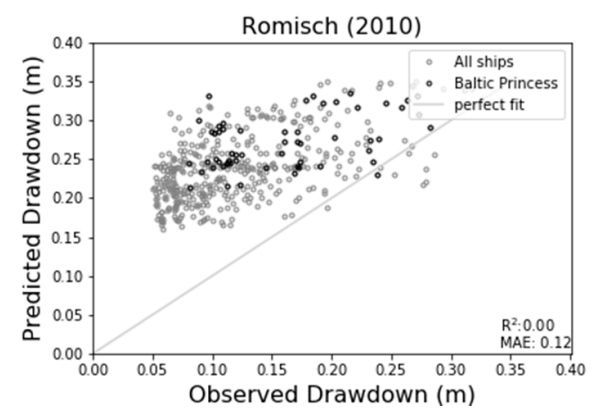

(e)

Figure 9. Calculated squat with empirical equations versus measured drawdown height at Nykvarnsholme and Björnhuvud for the existing empirical equations for squat of Huuska [29] (a); Yoshimura [34] (b); Eryuzlu [36] (c); Barrass [32] (d); and Römisch [35] (e). Grey markers represent all ships, whereas black markers only show data for the ship Baltic Princess. The drawdown from a single ship is included to show that the scatter is not related to the lack of information about the ship hull coefficient. The grey line displays the perfect fit between measured and predicted drawdown.

\subsection{New Predictive Equations}

In an effort to improve upon the predictive capability of the existing equations, a new semi-empirical equation was derived based on non-dimensional quantities emerging in a simple analytical model that considered the main governing physics. These quantities, employed in further analysis, were obtained from an expanded model of the drawdown and return velocity, which generalized the expression given by Equation (1). In this model, the drawdown and velocity were allowed to vary in space across the fairway based on an analytical solution. This solution was derived from the continuity and energy equations, assuming specific functional shapes for the water surface and return velocity across the fairway as proposed by Larson and Almström [44]. The shape was taken from a closed-form solution for the flow around a cylinder presented by Matviyenko et al. [45] but adapted to a passing ship. The derived analytical solution for a spatially varying drawdown made it possible to identify a number of non-dimensional groups that were used in a subsequent regression analysis. These non-dimensional groups included the ratio between distance to the shore and the ship width $(x / B)$, the ratio between the ship width and the fairway $(B / T)$, the ratio between the draught and the hydraulic depth $(d s / D)$, and the depth-based Froude number $(U / \sqrt{g D})$. In addition, the correlation analysis (see Table 2) between parameters and drawdown height showed a strong correlation between drawdown height and ship length. The ship length was included by a ratio between the ship length and draught. This ratio was selected since it gave a better predictability of the equation compared to using other parameters together with the ship length. Moreover, the depth-based Froude number is preferred overlength-based since the drawdown wave propagates over shallow water.

The optimum coefficient values for these dimensionless groups, which were combined into a power relationship, were obtained through regression analysis using the observed drawdown heights. Initially, the data set was divided into a calibration and validation set based on the location of the measurements. The approach proved not to be suitable since the coefficients became optimized for one 
fairway geometry. Utilizing both locations produces more generic coefficients. Hence, the regression analysis was performed by dividing the data set into one calibration and one validation set of equal size (i.e., $50 \%$ of the data for calibration and $50 \%$ for validation). Then, by randomly generating 100 different calibration and validation sets from the measurements, a multiple linear regression was made for each set to derive 100 sets of optimal coefficient values. This number of sets was sufficient to arrive at converged estimates of average values on the coefficients, which was confirmed by making simulations for an even larger number of generated data sets. The 100 sets of coefficients had an $R^{2}$ value ranging from 0.54 to 0.74 for the calibration sets, and an $R^{2}$ value ranging from 0.52 to 0.73 for the validation sets. The similar $R^{2}$ values for the calibration and validation sets indicated robustness and reliability of the obtained regression models. The set of coefficients being nearest to the converged average coefficient values was selected to be the set with the overall best fit to the measured data. Thus, the following coefficient values were obtained:

$$
\frac{S_{D} 2 g}{U^{2}}=0.22\left(\frac{U}{\sqrt{g D}}\right)^{0.42}\left(\frac{B}{x}\right)^{0.85}\left(\frac{B}{T}\right)^{0.32}\left(\frac{d s}{D}\right)^{1.46}\left(\frac{L}{d s}\right)^{0.80} .
$$

Results from applying Equation (1) for a typical set of calibration and validation data can be seen in Figure 10.

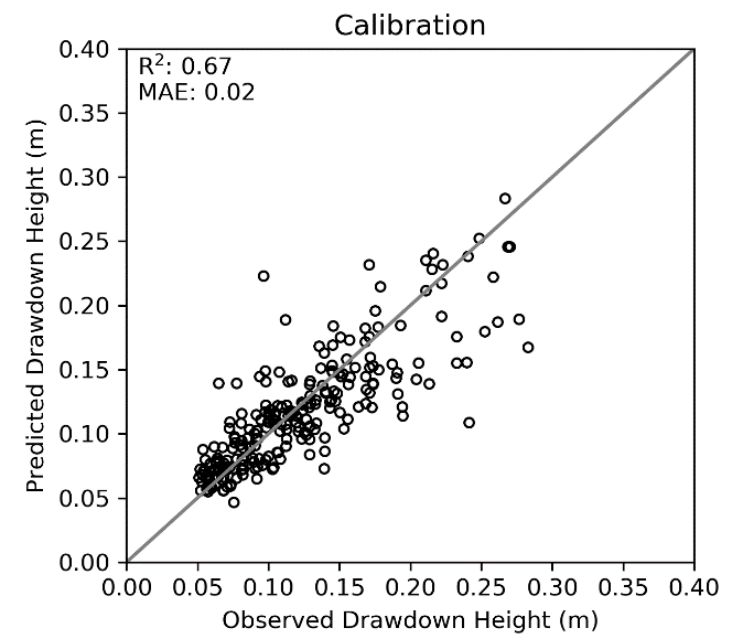

(a)

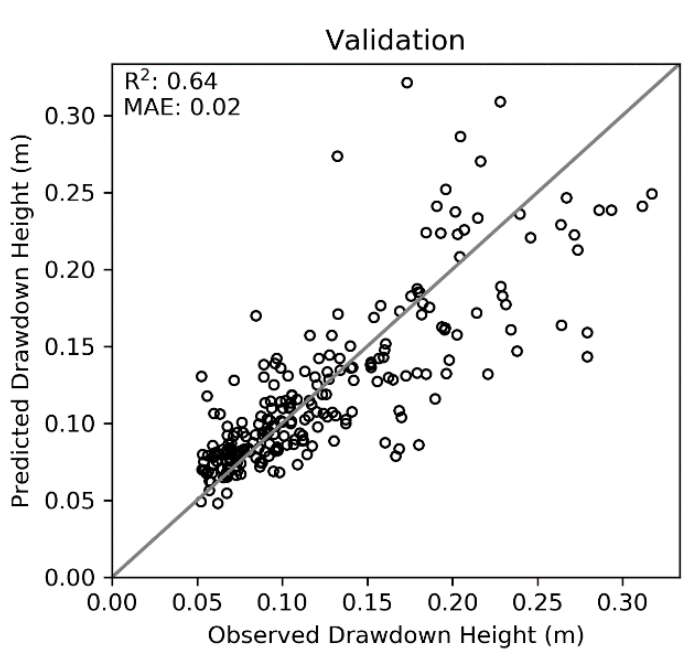

(b)

Figure 10. Predicted drawdown height with the proposed equation plotted against observed drawdown height for a typical data set used for calibration (a) and validation (b). The grey line displays the perfect fit between observed and predicted drawdown.

Since the drawdown period correlated with the drawdown height, an empirical equation for the drawdown period was obtained using the same approach as for the drawdown height (described above), with identical dimensionless groups employed, except for the normalization of the period. The period was normalized with the ship length, since there is a strong correlation between the period, ship speed and length in more narrow channels. The 100 set of coefficients had an $R^{2}$ value ranging from 0.57 to 0.74 , for the calibration sets and an $\mathrm{R}^{2}$ value ranging from 0.51 to 0.73 , for the validation sets. For the drawdown wave period, the following empirical equation was developed:

$$
\frac{T_{p} U}{L}=5.5\left(\frac{U}{\sqrt{g D}}\right)^{-0.50}\left(\frac{B}{x}\right)^{-0.40}\left(\frac{B}{T}\right)^{0.25}\left(\frac{d s}{D}\right)^{-0.77}\left(\frac{L}{d s}\right)^{-0.74}
$$


where $T_{p}$ is the drawdown period (s). Results from applying Equation (2) to a typical calibration and validation set can be seen in Figure 11.

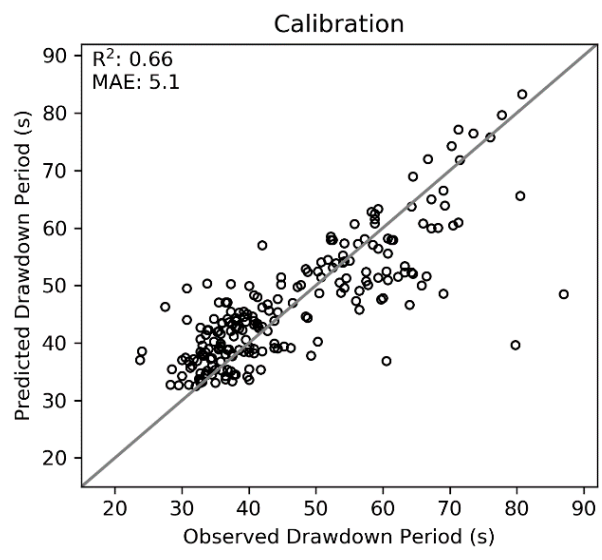

(a)

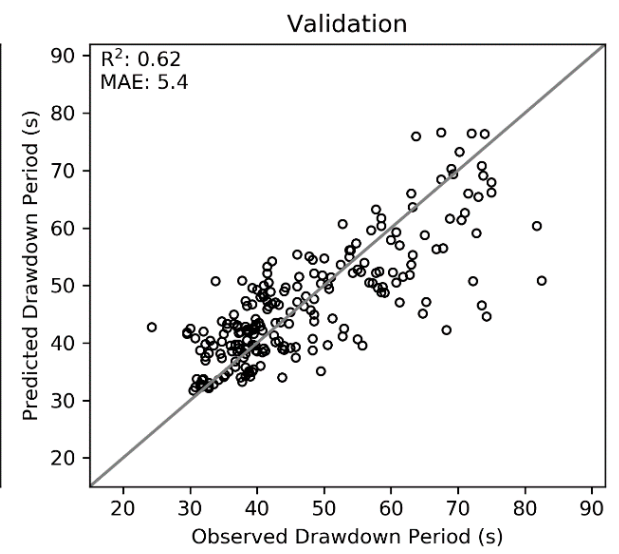

(b)

Figure 11. Predicted drawdown period with the newly derived equation plotted against observed drawdown period for a typical data set used for calibration (a) and validation (b). The grey line displays the perfect fit between observed and predicted drawdown.

The proposed equation for drawdown height was also applied to the entire data set resulting in an $\mathrm{R}^{2}$ value of 0.65 and a mean absolute error (MAE) of $0.02 \mathrm{~m}$ (Figure 12), to evaluate it under similar conditions to the previously evaluated existing equations presented in Figures 8 and 9. The present method led to a better equation for predicting drawdown height for our data set than the existing equations. Since no empirical equation was found in the literature for predicting the drawdown wave period, the derived equation cannot be compared with existing equations. Applying the equation for the drawdown period on the entire dataset resulted in an $\mathrm{R}^{2}$ value of 0.64 and an MAE of $5.2 \mathrm{~s}$.
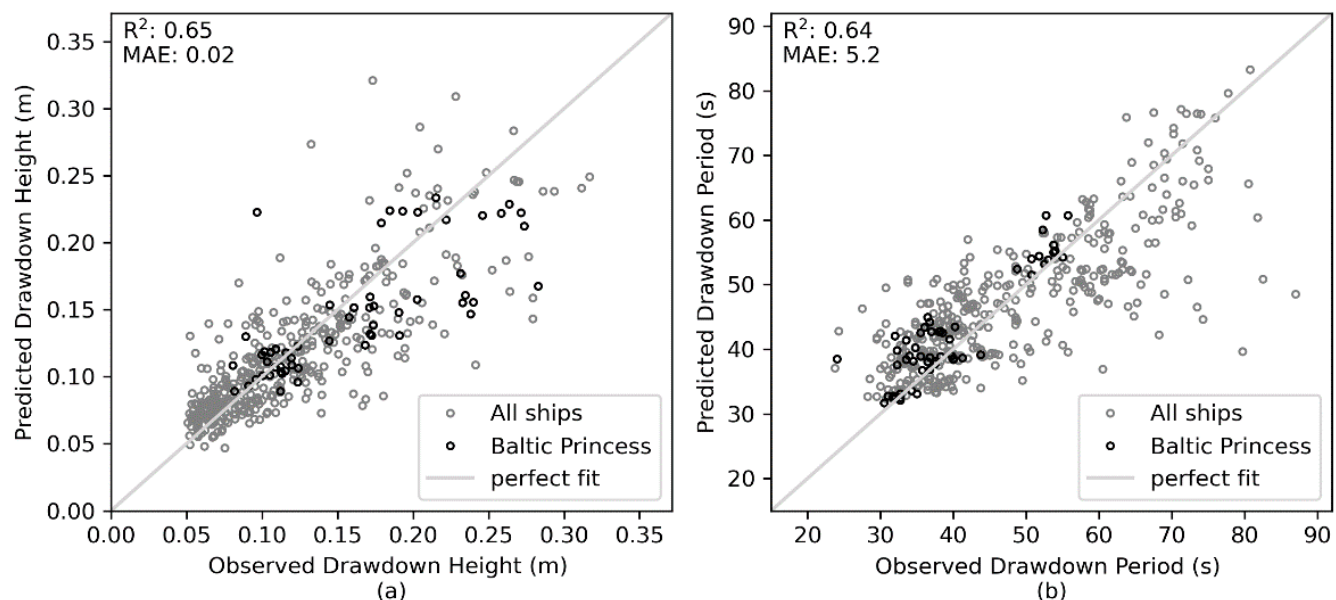

Figure 12. Predicted drawdown height (a) and period (b) with the newly derived equations plotted against the measurements for all data (grey markers) and for a single ship (black markers). The grey line displays the perfect fit between observed and predicted drawdown.

\section{Discussion}

This study illustrates the difficulties in using empirical equations to accurately predict properties of primary ship waves in large fairways relative to ship sizes. However, in this study the equations by Hochstein, Dand and White, Bhowmik, and Shijfs predicted wave heights in the right order of 
magnitude. Furthermore, when applied to a large number of ship passages they may produce a low mean absolute error.

The data set showed a rather small range in measured drawdown heights (see Figure 5), probably because of ships sailing with similar speeds and having hulls with comparable dimensions. Considering this limited range, the large scatter of drawdown heights in the data could not be easily explained by the parameters obtained from the AIS data (Figure 6). By analyzing individual ships, the scatter was still significant (see results for Baltic Princess in Figures 8, 9 and 12). Hence, the scatter in the data are most probably related other factors other than the hull geometry, such as the influence of the bathymetry (including the shoreline configuration) on the wave generation and propagation. The importance of bathymetry is supported by the observed difference in distributions of drawdown height for inbound and outbound ships at the two locations (see Figure 5). Analysis demonstrated the importance of considering the exact location where the drawdown was generated when determining its properties. Since the fairway is rather wide, the drawdown is generated locally around the ship and propagates towards shore as a free depression wave. This further complicates the analysis as different transformation processes will affect the properties of the drawdown wave recorded at the shore. Another possible explanation for the scatter is the ship dynamics (e.g., ship acceleration and retardation with associated inertial forces, often related to ships changing course, as well as maneuvering in the fairway). These actions may affect the wave generation. In conclusion, the properties of primary ship waves at the study site are not easily related to simple parameters identified as significant in the literature.

The evaluation of the investigated empirical equations showed that most of them could not predict the measured drawdown height for ships sailing through the study area, which involves a wide and deep fairway with ship sailing some distance from the shore. The low performance of these equations can be explained by the existing models being derived for specific fairways with a cross-section area that is smaller relative to the ship cross-section area. This implies limited applicability of these equations for fairways with a large cross-sectional area relative to the ship cross-section. Moreover, equations are mainly constrained to the geometry of the ships for which the equations were developed. Bhowmik [17] and Maynord [10] underestimate the drawdown in the Furusund data set since they are developed for inland channels where barges are a common type of vessel. Barges differ from ocean-going vessels by having a large ratio of length to draught.

The best fit, compared to measured data, was obtained with the equations by Hochstein [23] and Dand and White [25], having an $R^{2}=0.48$ and $R^{2}=0.43$, respectively, both yielding a mean absolute error of about $3 \mathrm{~cm}$. These two equations are both based on the blockage ratio and the velocity head in the Bernoulli equation. All equations derived for predicting drawdown height performed better than the squat equations. As expected, the assumption of squat being more or less equal to the drawdown at the shore is not a valid assumption for large fairways such as Furusund where the ship does not occupy a substantial portion of the fairway cross section.

As an alternative to the existing empirical equations for drawdown height, a new equation was derived based on regression analysis involving dimensionless groups derived from a simple analytical model based on the main physical processes. Different types of ship Froude numbers are often included in empirical equations for drawdown with the length scale based on the water depth or the ship length. The new equation includes the depth-based Froude number since the drawdown can be considered a shallow-water wave due to the ratio between the water depth and the wavelength. The blockage ratio did not appear in the final equation, but instead the ratios $\mathrm{B} / \mathrm{T}$ and $\mathrm{ds} / \mathrm{D}$ were separate quantities. The new equation performed better than the existing equations evaluated in this study with an $\mathrm{R}^{2}=0.65$ and a mean absolute error of $0.02 \mathrm{~m}$.

The period of the primary wave is especially critical for assessing ship wave impact on shores and protection measures, but no empirical equation for predicting the drawdown wave period was found in the literature. It is therefore not possible to assess the performance of the equation derived in this study towards other studies. However, the wave period correlates to the drawdown height. Therefore, 
it was possible to derive an equation for the wave period using the same dimensionless groups as the ones used for the drawdown height but with different coefficient values. The equation was able to satisfactorily predict the wave period.

The coefficients in the proposed equations are derived for conventional, ocean-going ships with a ship block coefficient of about 0.7 and for a speed range of about 8 to 12 knots. The equations are assuming a non-uniform drawdown and are thereby applicable in larger waterways.

\section{Conclusions}

The overall aim of this study was to characterize primary ship waves from measurements in an archipelagic navigational fairway and to evaluate the feasibility to use explicit, predictive equations for primary waves in such an environment. In total, 13 existing empirical equations were evaluated for a data set consisting of 466 ship passages that generated primary waves. The data were obtained through measurements in one of the main fairways in the Stockholm archipelago, using a capacitance staff gauge for water level measurements, which were combined with AIS data. The approach showed to be a cost-effective method for continuous measurements, producing large amounts of ship wave data and the possibility to relate wave properties to ship and fairway characteristics.

Simplified, predictive equations for ship waves can be very useful for initial estimates of primary wave heights or long-term impact assessment for shorelines along a fairway. Since no empirical equations to predict primary ship waves valid for fairways with large cross-sectional area were found in the literature, this study focused on evaluating 13 equations derived for channel/river waterways in order to assess their applicability in complex fairways. Only the equations by Hochstein [23], Dand and White [25], Bhowmik [17], and Shijfs [11] resulted in a reasonable agreement with the measured values by showing statistical significance. However, the best agreement was obtained through a regression analysis based on the observed wave data and physically derived non-dimensional groups, which yielded a coefficient of determination of $R^{2}=0.65$. No empirical equations were available in the literature to predict the period of the primary wave. Therefore, an equation for predicting the drawdown period was also derived using a regression approach.

All the empirical equations produced significant scatter for the studied data set, which probably occurred because the empirical formulas are not able to describe effects of the irregular bathymetry and the dynamic processes associated with ship maneuvering in the fairway. The proposed equation in this study showed better results than the existing equation. However before it is applied to another site it should preferably be validated with measurements from other locations in archipelagic settings.

If data on primary ship waves are available at the particular site of interest, it might be better to develop a semi-empirical equation based on the data. This development is preferably done through regression analysis involving the dimensionless groups relevant to the physical description of primary ship waves used in this study. As shown, the approach yielded a higher $\mathrm{R}^{2}$ value compared to the best performing equations from the literature. Limitations of the approach are that it may require extensive measurements and that the equations are only valid at the specific measurement location and over the range of collected parameter values. Continuous water level measurements coupled with AIS data is an efficient method for collecting extensive measurements, as shown in this study.

Author Contributions: Conceptualization, M.L. and B.A.; methodology, M.L. and B.A.; software, B.A.; validation, B.A.; formal analysis, B.A.; investigation, B.A.; resources, M.L.; data curation, B.A.; writing-original draft preparation, B.A.; writing-review and editing, M.L.; visualization, B.A.; supervision, M.L.; project administration, M.L.; funding acquisition, M.L. All authors have read and agreed to the published version of the manuscript.

Funding: This work was supported by the Swedish Transport Administration [grant number TRV 2015/85109]; the Swedish Agency for Marine and Water Management [grant number 1211-16]; the Stockholm County Administrative board [grant number 500-12853-2016]; and the Swedish Geotechnical Institute [grant number 16139].

Acknowledgments: We are grateful to Lars Granath at Hydrographica for conducting and sharing field measurement of the ship waves. We also appreciate the advice and input given by Caroline Hallin at Lund University on this paper. Finally, we thank the anonymous reviewers for their constructive comments and critical questions that significantly improved the paper. 
Conflicts of Interest: The authors declare no conflict of interest. The funders had no role in the design of the study; in the collection, analyses, or interpretation of data; in the writing of the manuscript, or in the decision to publish the results.

\section{Appendix A}

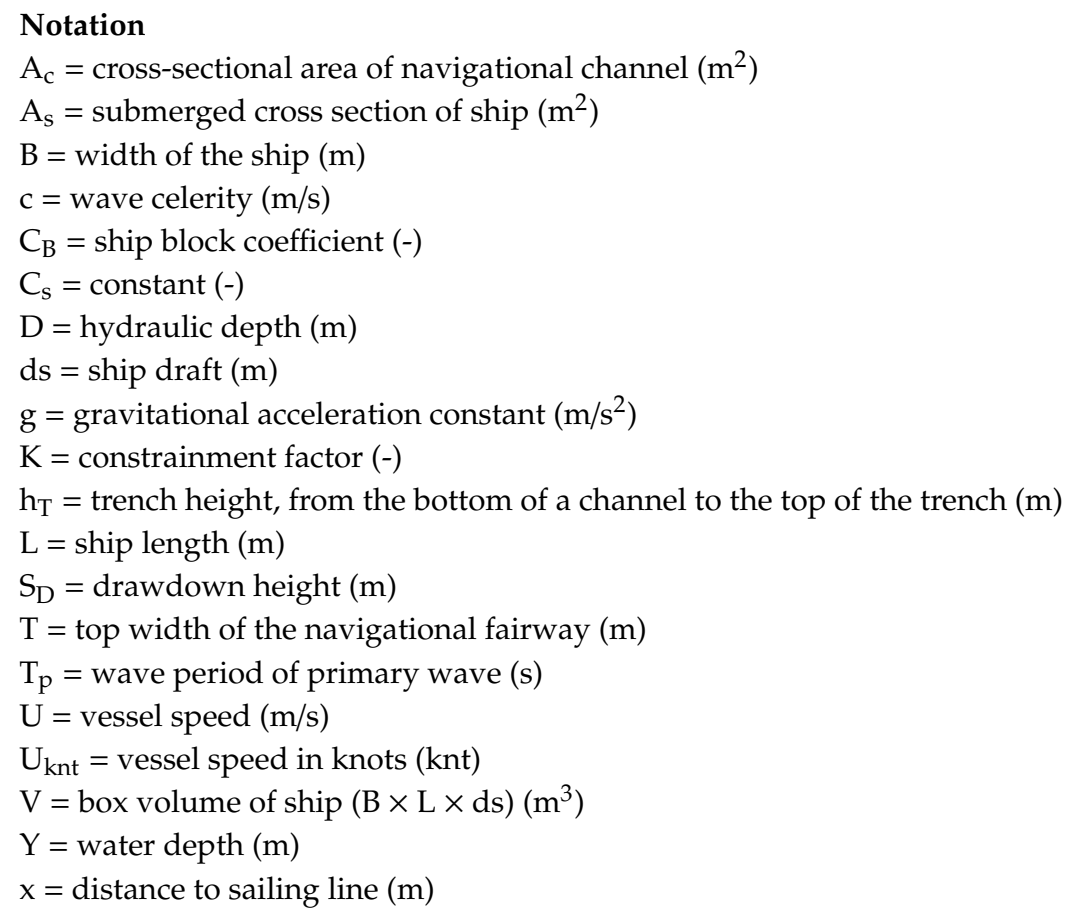

\section{Appendix B}

The equations in Appendix B have been rewritten to be consistent with the nomenclature used in the present paper.

Appendix B.1 Empirical Equations for Drawdown

Empirical equations from Shijfs [11]:

$$
1=\frac{A_{s}}{A_{c}}+\frac{S_{D}}{D}-\frac{1}{\sqrt{1+\frac{2 g S_{D}}{u^{2}}}},
$$

where $S_{D}$ is the drawdown height, $D$ is the hydraulic mean depth, $A_{S}$ is the submerged cross-sectional area of the ship, $A_{c}$ is the cross-sectional area of the fairway, $g$ is the gravitational constant, and $U$ is the ship speed.

Hochstein's equation (units in feet) for drawdown is,

$$
\begin{gathered}
S_{D}=U^{2}(a-1) \frac{B_{1}}{2 g} \\
a=\left(\frac{A_{c}}{A_{c}-A_{s}}\right)^{2.5} \text { and } B_{1}=\left\{\begin{array}{c}
0.3 e^{\frac{1.8 u}{K \sqrt{g D}}} \frac{U}{K \sqrt{{ }^{D D}}} \leq 0.65 \\
1.0 \frac{U}{K \sqrt{g D}}>0.65
\end{array},\right.
\end{gathered}
$$

where $S_{D}$ is the drawdown height, $D$ is the hydraulic mean depth, $A_{s}$ is the submerged cross-sectional area of the ship, $A_{\mathcal{C}}$ is the cross-sectional area of the fairway, $g$ is the gravitational constant, $U$ is the ship speed, and, $K$ is a constrainment factor that is a function of the blockage ratio and the ratio of ship length to beam ( $K=0.7$ used in this paper, which represents the average ship in the data set). 
Gelencser's [14] equation is given by,

$$
S_{D}=2 \cdot 10^{-6}\left(\left(U A_{s} \frac{L^{2}}{x \sqrt{A_{c}}}\right)^{1 / 3}\right)^{2.8}
$$

where $S_{D}$ is the drawdown height, $A_{s}$ is the submerged cross-sectional area of the ship, $A_{c}$ is the cross-sectional area of the fairway, $U$ is the ship speed, $L$ is the ship length, and $x$ is the distance from the ship to the shoreline.

Dand and White [25] present their equation as,

$$
S_{D}=8.8\left(\frac{A_{c}}{A_{s}}\right)^{-1.4} \cdot \frac{U^{2}}{2 g},
$$

where $S_{D}$ is the drawdown height, $A s$ is the submerged cross-sectional area of the ship, $A_{c}$ is the cross-sectional area of the fairway, $g$ is the gravitational constant, and $U$ is the ship speed.

Bhowmik et al. [17] define the equation for drawdown as:

$$
S_{D}=1.03 \frac{U^{2}}{2 g}\left(\frac{A_{s}}{A_{c}}\right)^{0.81}\left(\frac{L}{x}\right)^{0.31},
$$

where $S_{D}$ is the drawdown height, $A_{s}$ is the submerged cross-sectional area of the ship, $A_{c}$ is the cross-sectional area of the fairway, $g$ is the gravitational constant, $U$ is the ship speed, $L$ is the ship length, and $x$ is the distance from the shore to the ship.

Maynord [10] expresses the drawdown as,

If $x / T$ is between 0 and 0.5 :

$$
S_{D}=\left(\frac{\left(U+\left(\left(U \frac{A_{c}}{A_{c}-A_{s}}-U\right)\left(1.9-1.29 \frac{U}{U_{L}}\right)\right)\right)^{2}}{2 g}-\frac{U^{2}}{2 g}\right)\left(1.65-1.3 \frac{x}{T}\right) \sqrt{0.75 \cdot\left(\frac{A_{c}}{A_{s}}\right)^{0.18}} e^{3 \ln \left(\frac{1}{0.75 \cdot\left(\frac{A_{c}}{A_{s}}\right)^{0.18}}\right)}
$$

If $x / T$ is between 0.5 and 1.0 :

$$
\begin{aligned}
& S_{D}=\left(\frac{\left(U+\left(\left(U \cdot \frac{A_{c}}{A_{c}-A_{s}}-U\right)\left(1.9-1.29 \frac{U}{U_{L}}\right)\right)\right)^{2}}{2 g}-\frac{U^{2}}{2 g}\right)\left(1.35-0.7 \frac{x}{T}\right) \sqrt{0.75\left(\frac{A_{c}}{A_{s}}\right)^{0.18}} e^{3 \ln \left(\frac{1}{0.75\left(\frac{A_{c}}{A_{s}}\right)^{0.18}}\right)}, \\
& U_{L}=\sqrt{2 g D\left(\frac{A_{s}}{A_{c}}+1.5\left(\frac{U_{L}^{2}}{g D}\right)^{\frac{1}{3}}-1\right)}
\end{aligned}
$$

where $S_{D}$ is the drawdown height, $A_{s}$ is the submerged cross-sectional area of the ship, $A_{c}$ is the cross-sectional area of the fairway, $g$ is the gravitational constant, $U$ is the ship speed, $T$ is the top width of the fairway, $x$ is the distance from the shore to the ship, and $D$ is the hydraulic mean depth.

Kriebel et al. [9] express their equation as,

$$
S_{D}=d s\left(0.0026 C_{B}-0.001\right) e^{\left(\frac{-215.8 d s}{L}+26.4\right) \frac{U}{\sqrt{8 L}} e^{\frac{2.35\left(1-C_{B}\right) d s}{Y}},}
$$

where $d s$ is the ship draft, $C_{B}$ is the ship block coefficient, $L$ is the ship length, $U$ is the ship speed, $g$ is the gravitational constant, and $Y$ is the water depth.

The Rock Manual's [26] equation is described as,

$$
S_{D}=\frac{U^{2}}{2 g}\left(\left(1.4-0.4 \frac{U}{F_{L} \sqrt{g D}}\right) \cdot\left(\frac{A_{\mathcal{c}}}{A_{c}-A_{s}-S_{D} T}\right)^{2}-1\right)
$$




$$
F_{L}=\left(\frac{2}{3}\left(1-\frac{A_{s}}{A_{c}}+0.5 F_{L}^{2}\right)\right)^{3 / 2},
$$

where $S_{D}$ is the drawdown height, $U$ is the ship speed, $g$ is the gravitational constant, $D$ is the hydraulic mean depth, $A_{\mathcal{C}}$ is the cross-sectional area of the fairway, $A_{s}$ is the cross-sectional area of the ship, and $T$ is the top width of the fairway.

Appendix B.2 Empirical Equations for Squat

Huuska's expression for bow squat is given by,

$$
\begin{gathered}
S_{b}=C_{s} \frac{C_{B} L B d s}{L^{2}} \frac{\left(\frac{U}{\sqrt{g Y}}\right)^{2}}{\sqrt{1-\left(\frac{U}{\sqrt{g Y}}\right)^{2}}} K_{s} \\
K_{s}=\left\{\begin{array}{c}
7.45 \frac{A_{s}}{A_{c} K_{1}}+0.76 \frac{A_{s}}{A_{c} K_{1}}>0.03 \\
1.0 \frac{A_{s}}{A_{c} K_{1}} \leq 0.03
\end{array},\right.
\end{gathered}
$$

where $S_{b}$ is the bow squat, $C_{S}$ is a correction factor depending on $C_{B}, C_{B}$ is the ship block coefficient, $L$ is the length of the ship, $B$ is the beam of the ship, $d s$ is the draught of the ship, $U$ is the ship speed, $g$ is gravitational constant, $Y$ is the water depth, $A_{s}$ is the ship cross-section area, $A_{c}$ is the fairway cross-section area, and $K_{1}$ is given as a plotted function of blocking ratio and trench height ratios in Huuska [29].

The Barass equation for the squat is,

$$
S_{M A X}=0.0574 C_{B}\left(\frac{A_{s}}{A_{c}}\right)^{0.76} U_{k n t^{\prime}}^{2}
$$

where $S_{M A X}$ is the maximum squat, $C_{B}$ is the ship block coefficient, $A_{s}$ is the ship cross-section area, $A_{c}$ is the fairway cross-section area, and $U_{k n t}$ is the ship speed in knots.

Yoshimuras equation for bow squat is as follows:

$$
S_{b}=\left(\left(0.7+1.5 \frac{d s}{Y}\right)\left(\frac{C_{B} B}{L}\right)+15 \frac{d s}{Y}\left(\frac{C_{B} B}{L}\right)^{3}\right) \frac{U^{2}}{g},
$$

where $S_{b}$ is the bow squat, $d s$ is the draught of the ship, $Y$ is the water depth, $C_{B}$ is the ship block coefficient, $B$ is the beam of the ship, $L$ is the length of the ship, $U$ is the ship speed, and $g$ is gravitational constant.

The Römisch equation for bow and stern squat is:

$$
\begin{gathered}
S_{b}=C_{V} C_{F} K_{\Delta T} d s \\
S_{s}=C_{V} K_{\Delta T} d s \\
C_{V}=8\left(\frac{U}{U_{c r}}\right)^{2}\left(\left(\frac{U}{U_{c r}}-0.5\right)^{4}+0.0625\right) \\
C_{F}=\left(\frac{10 C_{B}}{L / B}\right)^{2} \\
K_{\Delta T}=0.155 \sqrt{\frac{Y}{d s}}
\end{gathered}
$$




$$
U_{c r}=\left\{\begin{array}{c}
0.58\left(\frac{Y}{d_{s}} \frac{L}{B}\right)^{0.125} \sqrt{g Y} \text { Unrestricted Channel } \\
\left(2 \sin \left(\frac{\operatorname{Arcsin}\left(1-\frac{A_{s}}{A_{c}}\right)}{3}\right)\right)^{1.5} \sqrt{g D} \text { Canal }
\end{array},\right.
$$

where $S_{b}$ is the bow squat, $S_{s}$ is the stern squat, $d s$ is the ship draught, $U$ is the ship speed, $C_{B}$ is the ship block coefficient, $L$ is the ship length, $B$ is the ship beam, $Y$ is the channel depth, $g$ is the gravitational constant, $A_{s}$ is the submerged ship cross-section area, $A_{\mathcal{c}}$ is the fairway cross-section area, and $D$ is the hydraulic mean depth.

Eryuzlu's equation is given by:

$$
\begin{gathered}
S_{b}=0.298 \frac{Y^{2}}{d s}\left(\frac{U}{\sqrt{g d s}}\right)^{2.289}\left(\frac{Y}{d s}\right)^{-2.289} K_{b} \\
K_{b}=\left\{\begin{array}{l}
\frac{3.1}{\sqrt{\frac{T}{B}} \frac{T}{B}<9.61} \\
1 \frac{T}{B} \geq 9.61
\end{array},\right.
\end{gathered}
$$

where $S_{b}$ is the bow squat, $Y$ is the channel depth, $d s$ is the ship draught, $U$ is the ship speed, $g$ is the gravitational constant, $B$ is the ship beam, and $T$ is the fairway width.

\section{References}

1. Barbier, E.B.; Hacker, S.D.; Kennedy, C.; Kock, E.W.; Stier, A.C.; Sillman, B.R. The value of estuarine and coastal ecosystem services. Ecol. Monogr. 2011, 81, 169-193. [CrossRef]

2. Sorensen, R.M. Prediction of Vessel-Generated Waves with Reference to Vessels Common to the Upper Mississippi River System; ENV Report 4 (1997); US Army Corps of Engineers: Washington, DC, USA, 1997.

3. Gabel, F.; Lorenz, S.; Stoll, S. Effects of ship-induced waves on aquatic ecosystems. Sci. Total Environ. 2017, 601-602, 926-939. [CrossRef] [PubMed]

4. De Roo, S.; Troch, P. Field monitoring of ship wave action on environmentally friendly bank protection in a confined waterway. J. Waterw. Port Coast. Ocean Eng. 2013, 139, 527-534. [CrossRef]

5. David, C.G.; Roeber, V.; Goseberg, N.; Schlurmann, T. Generation and propagation of ship-borne waves-Solutions from a Boussinesq-type model. Coast. Eng. 2017, 127, 170-187. [CrossRef]

6. Gharbi, S.; Valkov, G.; Hamdi, S.; Nistor, I. Numerical and field study of ship-induced waves along the St. Lawrence Waterway, Canada. Nat. Hazards 2010, 54, 605-621. [CrossRef]

7. MPC de Jong, D.; Roelvink, S.P.; Reijmerink, C. Breederveld, Numerical modelling of passing-ship effects in complex geometries and on shallow water. In Proceedings of the PIANC: Smart Rivers 2013, Leige, Belgium and Maastricht, The Netherlands, 23-27 September 2013. [CrossRef]

8. Osborne, P.D.; Macdonald, N.; De Waal, N. Full-scale Measurements and Impact Studies With High Speed Foil-Assisted Catamarans in a Wake Sensitive Area. In Proceedings of the 10th International Conference on Fast Sea Transportation FAST 2009, Athens, Greece, 5-8 October 2009.

9. Kriebel, D.; Seelig, W.; Judge, C. Development of a Unified Description of Ship-Generated Waves. In Proceedings of the U.S. Section PIANC Annual Meeting, Roundtable, and Technical Workshops (CD-ROM), PIANC USA, Alexandria, VA, USA, 2003.

10. Maynord, S. Return Velocity and Drawdown in Navigable Waterways; Technical Report HL-96-7; US Army Corps of Engineers: Vicksburg, MS, USA, 1996.

11. Schijf, J.B. Protection of Embankments and Bed in Inland and Maritime Waters, and in Overflow or Weirs. In XVII International Navigation Congress, Lisbon, Section I. Lisbon; PIANC: Brussels, Belgium, 1949; pp. 61-78.

12. Bertram, V. Practical Ship Hydrodynamics, 2nd ed.; Butterworth-Heinemann: Oxford, UK, 2000. [CrossRef]

13. Schiereck, G. Introduction to Bed, Bank and Shore Protection, 1st ed.; Delft University Press: Delft, The Netherlands, 2001.

14. Gelencser, G. Drawdown Surge and Slope Protection, Experimental Results. In 24th International Navigation Congress; Leningrad, Soviet Union; PIANC: Brussels, Belgium, 1977; pp. 21-40. 
15. Göransson, G.; Larson, M.; Althage, J. Ship-Generated Waves and Induced Turbidity in the Göta Älv River in Sweden. J. Waterw. Port Coast. Ocean Eng. 2014, 140, 3. [CrossRef]

16. Herbich, J.B.; Schiller, R. Surges and Waves Generated by Ships in a Constricted Channel. In Proceedings of the 19th International Conference on Coastal Engineering, Houston, TX, USA, 3-7 September 1984; pp. 3213-3226.

17. Bhowmik, N.G.; Demissie, M.; Guo, C.Y. Waves and Drawdown Generated by River Traffic on the Illinois and Mississippi Rivers; University of Illinois Water Resources Center: Champaign, IL, USA, 1981.

18. Parnell, K.E.; Soomere, T.; Zaggia, L.; Rodin, A.; Lorenzetti, G.; Rapaglia, J.; Scarpa, G.M. Ship-induced solitary Riemann waves of depression in Venice Lagoon. Phys. Lett. Sect. A 2015, 379, 555-559. [CrossRef]

19. Jansen, P.P.; Schijf, J.B. Inland Navigation. In Proceedings of the XVIIIth International Navigation Congress, Rome, Italy, 1953; pp. 175-197.

20. Briggs, M.; Vantorre, M.; Uliczka, K.; Debaillon, P. Chapter 26 Prediction of Squat for Underkeel Clearance. In Handbook of Coastal and Ocean Engineering; Young, Y.C., Ed.; World Scientific: Los Angeles, CA, USA, 2009. [CrossRef]

21. Thiele, A. Schiffswiderstand af Canalen. Zent. Bauverwalt. 1901, 56, 345-347.

22. Gates, E.T.; Herbich, J.B. Mathematical Model to Predict the Behavior of Deep-Draft Vessels in Restricted Waterways, Ocean Engineering Program; TAMU-SG-77-206, Report No. 200; Texas A\&M University: Dallas, TX, USA, 1977.

23. Hochstein, A. Navigation Use of Industrial Canals; Water Transportation, Moscow Publishing House: Moscow, Russia, 1967.

24. Hochstein, A.; Adams, C. Influence of vessel movements on stability of restricted channels. J. Waterw. Port Coast. Ocean Eng. 1989, 115, 444-465. [CrossRef]

25. Dand, I.W.; White, W.R. Design of Navigation Canals. In 2nd Symposium, Aspects of Navigability of Constraint Waterways; Including Harbour Entrances: Delft, The Netherlands, 1978; pp. 1-9.

26. CIRIA; CUR; CETMEF. The Rock Manual: The Use of Rock in Hydraulic Engineering, 2nd ed.; No. C683; CIRA: London, UK, 2007.

27. Tuck, E.O. Shallow-water flows past slender bodies. J. Fluid Mech. 1966, 26, 81-95. [CrossRef]

28. Hooft, J.P. The behaviour of a ship in head waves at restricted water depths. Int. Shipbuild. Prog. 1974, 21, 367-390. [CrossRef]

29. Huuska, O. The Evaluation of Underkeel Clearances in Finnish Waterways; Report No. 9; University of Technology, Ship Hydrodynamics Laboratory: Helsinki, Finland, 1976.

30. Guliev, U.M. On Squat Calculations for Vessels Going in Shallow Water and Through Channels. PIANC Bull. 1971, 1, 17-20.

31. ICORELS (International Comission of Reception of Large Ships). Report of Working Group IV, PIANC Bulletin No. 35; Supplement; PIANC: Brussels, Belgium, 1980.

32. Barrass, C.B. The phenomen of ship squat. Int. Shipbuild. Prog. 1979, 26, 44-47. [CrossRef]

33. Barrass, C.B. Ship squat-A reply. Nav. Archit. November 1981, 268-272.

34. Yoshimura, Y. Mathematical Model for the Manoeuvring Ship Motion in Shallow Water. J. Kansai Soc. Nav. 1986, 211, 115-126.

35. Römisch, K. Empfehlungen zur Bemessung von Hafeneinfahrten. In Wasserbauliche Mitteilungen der Technischen Universit at Dresden, Heft 1; Technischen Universit Dresden: Dresden, Germany, 1989; pp. $39-63$.

36. Eryuzlu, N.E.; Cao, Y.L.; D'Agnolo, F. Underkeel Requirements for Large Vessels in Shallow Waterways. In Proceedings of the 28th International Navigation Congeress, Sevilla, Spain, 22-27 May 1994; PIANC: Brussels, Belgium; pp. 17-25.

37. Forsberg, M. Ruttval i Stockholms Skärgård_En Fallstudie om Ruttval i Furusunds- och Sandhamnsleden; Chalmers University of Technology: Gothenburg, Sweden, 2017.

38. Granath, L. Stranderosionsrisker i Samband med Anlöp av "Navigator of the Seas"; Swedish Maritime Administration, Ports of Stockholm: Stockholm, Sweden, 2007.

39. Daleke, O.; Hedström, H.; Nissar, K. Fartygstrafikens Miljöeffekter i Skärgården (No. 303); Länsstyrelsen i Stockholms län: Stockholm, Sweden, 1989.

40. Hedén, M.; Sannel, B. Vass som Indikator på Stranderosion Längs Farled i Stockholms Skärgård (No. 1992:9); Länsstyrelsen i Stockholms län: Stockholm, Sweden, 1992.

41. Granath, L. Farledsstränders Erosionskänslighet_Inventering av Strandtyper och skador i Stockholms Skärgård; No. Rapport 1992:10; Department of Physical Geography, Stockholm University: Stockholm, Sweden, 1992. 
42. Granath, L. Erosionsutvecklingen i Furusundsleden 2015; Swedish Transport Administration, Swedish Maritime Administration, Ports of Stockholm: Stockholm, Sweden, 2015.

43. Granath, L. Vågmätningar i Furusundsleden 2014-Utredning om Vågbildning och Vågenergier från olika Fartygskategorier; Swedish Transport Administration, Swedish Maritime Administration, Ports of Stockholm: Stockholm, Sweden, 2015.

44. Larson, M.; Almström, B. Varying Drawdown and Return Velocity around Ships in Restricted Waterways. Technical Note (in Preparation). J. Waterw. Port Coastal Ocean Eng. 2020.

45. Matviyenko, O.V.; Daneyko, O.I.; Moreva, T.A. Free Surface form Determination in Flow around Bridge Piers, Vestnik; NN 1-4: 2013; Tomsk State University of Architecture and Building: Tomsk, Russia, 2013; pp. 43-48.

(C) 2020 by the authors. Licensee MDPI, Basel, Switzerland. This article is an open access article distributed under the terms and conditions of the Creative Commons Attribution (CC BY) license (http://creativecommons.org/licenses/by/4.0/). 